\title{
Size and burden of mental disorders in Europe-a critical review and appraisal of 27 studies
}

\author{
Hans-Ulrich Wittchen ${ }^{\text {a,b,* }}$, Frank Jacobi ${ }^{\text {b }}$ \\ a Clinical Psychology and Psychotherapy, Technical University of Dresden, Dresden, Germany \\ b Max Planck Institute of Psychiatry, Munich, Germany
}

\begin{abstract}
Epidemiological data on a wide range of mental disorders from community studies conducted in European countries are presented to determine the availability and consistency of prevalence, disability and treatment findings for the EU. Using a stepwise multimethod approach, 27 eligible studies with quite variable designs and methods including over 150,000 subjects from 16 European countries were identified. Prevalence: On the basis of meta-analytic techniques as well as on reanalyses of selected data sets, it is estimated that about 27\% (equals 82.7 million; 95\% CI: 78.587.1) of the adult EU population, 18-65 of age, is or has been affected by at least one mental disorder in the past 12 months. Taking into account the considerable degree of comorbidity (about one third had more than one disorder), the most frequent disorders are anxiety disorders, depressive, somatoform and substance dependence disorders. When taking into account design, sampling and other methodological differences between studies, little evidence seems to exist for considerable cultural or country variation. Disability and treatment: despite very divergent and fairly crude assessment strategies, the available data consistently demonstrate (a) an association of all mental disorders with a considerable disability burden in terms of number of work days lost (WLD) and (b) generally low utilization and treatment rates. Only $26 \%$ of all cases had any consultation with professional health care services, a finding suggesting a considerable degree of unmet need. The paper highlights considerable future research needs for coordinated EU studies across all disorders and age groups. As prevalence estimates could not simply be equated with defined treatment needs, such studies should determine the degree of met and unmet needs for services by taking into account severity, disability and comorbidity. These needs are most pronounced for the new EU member states as well as more generally for adolescent and older populations.
\end{abstract}

Keywords: Anxiety; Depression; Addiction; Disability; Schizophrenia; Epidemiology

\section{Introduction}

Despite a considerable number of regional or national epidemiological studies on single diagnoses or groups of disorders in some European states (see e.g. Weissman et al., 1992, 1994, 1996, 1997, 1999), there have so far been no systematic attempts to describe comprehensively the size and burden of mental disorders for the European Union member states. As a consequence, it is unknown what proportion of the total EU population is affected by what type of mental disorder, how many children and adolescents and how many adults or elderly citizens suffer from mental disorders and whether these estimates differ by region, country and culture. Due to the lack of previous systematic inquiries in this domain, it is also unknown in which countries and for what types of disorders epidemiological studies have ever been conducted and to what degree these studies have come to similar results and conclusions. The lack of such EU-wide information is also a core obstacle to the adequate estimation of (a) the total burden associated with these disorders (Olesen and Leonardi, 2003), (b) the degree of met and unmet needs for treatment and intervention, (c) the patterns and 
costs of treatment and (d) the health-economic implications and total direct and indirect costs for EU nations. Acknowledging the pressing need for such data, the European College of Neuropsychopharmacology (ECNP) and the European Brain Council (EBC) as the joint representation of professional and health care institutions for mental and neurological disorders have recently commissioned a Task Force to conduct a systematic analysis of all available epidemiological studies in the EU (http://www.ebc-eurobrain.net). The analysis should cover a wide range of mental and neurological disorders (disorders of the brain) in order to describe, and if possible estimate comprehensively, the „size and scope“ of these disorders in the EU; areas needing increased future research attention should be highlighted. Furthermore, data on the burden as well as the direct and indirect costs associated with mental disorders should be critically reviewed or collected to serve as input for EU-wide cost analyses and projections.

For various reasons the estimation of the prevalence of mental disorders in the EU (i.e. how widespread is a specific disorder or a group of disorders?) is difficult: (1) EU-wide studies or systematic data collections on the prevalence of mental disorders are not available, except for a few cross-national comparisons for a restricted range of disorders. (2) The term „mental disorders“ includes hundreds of different clinical conditions (DSM-IV, American Psychiatric Association, 1994; ICD-10, World Health Organization, 1993), of which only some have ever been systematically explored in epidemiological studies in the EU or elsewhere. Thus, any epidemiological study estimating the total size and burden of mental disorders is necessarily more or less incomplete. (3) It is also problematic simply to add up prevalence estimates for single disorders within or across studies, because most mental disorders are associated with one another (comorbidity; Wittchen, 1996a,b). Thus adding up prevalences leads to double counting and inflated overall rates. (4) The diagnostic and methodological standards of community studies on mental disorders vary widely making direct comparisons difficult. (5) The wider EU consists of 25 states from different language areas, each of which with different sociodemographic and socioeconomic characteristics (OECD, 2005), different cultural, legal, social and health care system-related traditions (i.e. mental health care provider and reimbursement; Coulter and Magee, 2003), and different psychopathological traditions (i.e. diagnostic habits and definitions; Wittchen, 2001). All of these factors have been shown to complicate both the conduct of studies as well as interpretations of findings. (6) Unlike the long US tradition of fairly regular, large-scale community and general population studies with uniform methods and designs (i.e. ECA, Robins and Regier, 1991; NCS, Kessler et al., 1994; NCS-R, Kessler et al., 2004), there is no such tradition yet in the EU. Only a few EU countries (such as the UK, The Netherlands and Germany) have actually put the implementation of such national epidemiological studies high on their agenda so far.

Nevertheless, there is a considerable mass of epidemiological research in the EU. In fact, in addition to a substantial number of regional and country-specific epidemiological studies of various kinds (cross-sectional and longitudinal, community and administrative), numerous other sources of epidemiological collections are available, reflecting the extremely rich European tradition in this field (Wittchen, 2004). The core disadvantage of these data, however, is that they lack the necessary degree of standardisation concerning methods, design, constructs and instruments; thus making direct comparisons or meta-analytic approaches difficult. Some of these individual studies have already been critically reviewed elsewhere, for example in the context of international diagnosis-specific reviews (Andrade et al., 2000, 2003; Bijl et al., 2003; Coulter and Magee, 2003; Fryers et al., 2004; Kessler, 2004; Sartorius et al., 1993; Vega et al., 2002; Weissman et al., 1992, 1994, 1996, 1997, 1999; Wittchen et al., 2003; Wittchen, 2004). However, none of these publications has ever 
addressed specifically the core questions about the availability and the consistency of prevalence findings in the European Union member states.

Beyond prevalence, the lack of systematic data and knowledge is even more pronounced with regard to data on impairments and disabilities associated with mental disorders in the EU. Such data have not only much-disputed major public health and policy implications (Narrow et al., 2002; Kessler et al., 2003), but are also essential for estimating the cost burden. Beyond the estimations from the World Health Organization's Burden of Disease study (Murray and Lopez, 1996; for the EU: Olesen and Leonardi, 2003), only few large-scale epidemiological community studies are available that provide reliable information for at least some countries and/or at least some diagnoses on work loss days (WLD), „quality of life“ (Bijl and Ravelli, 2000a; ESEMeD/MHEDEA 2000 Investigators, 2002, 2004b; Jacobi et al., 2004b; Kessler and Frank, 1997). Another critical area is the question to what degree mental disorders are recognized, treated and managed in the general health care sector and the mental health care specialty sector. Beyond general administrative statistics, to our knowledge no EU-wide studies are available providing some information about the number of health care contacts by sector (general health care, specialist mental health care, in- and outpatient) as well as about types of intervention (drug, psychological treatment) (Wittchen, 2004).

Against this background, the primary aims of this paper are to review systematically all available epidemiological data on a wide range of mental disorders from community studies conducted in European countries and to determine the availability and the consistency of prevalence, disability and treatment findings. A further attempt is made to estimate the total prevalence of mental disorders across all EU states and to identify areas with particularly pronounced unmet research needs.

\section{Methods}

A stepwise multimethod study approach was adopted consisting of (a) iterative literature searches for epidemiological publications and subsequent data analyses of published material, (b) reanalyses of existing accessible epidemiological data sets and (c) structured expert inquiries and a questionnaire survey with experts in all EU countries. We considered only those studies conducted in community samples and reporting prevalence estimates for established diagnoses of mental disorders (according to criteria of DSM-III, DSM-IIIR or DSM-IV, American Psychiatric Association, 1980, 1987, 1994; or ICD-10, World Health Organization, 1993) or those using at least instruments with explicit diagnostic criteria that allow such inferences. As explicit diagnostic criteria were largely unavailable before the 1980s, the literature and study search was by and large restricted accordingly.

\subsection{Literature search and criteria for inclusion}

In an initial step, we performed a series of database searches (Web of Science, Medline, Psycinfo) to identify all epidemiological studies on mental disorders conducted in European regions. The first search covered the time period 1980 to 2003 with the following key words and related terms: epidemiology, prevalence, incidence, community, general population, mental disorders, psychiatric diagnoses/ diseases and over 15 specific diagnostic terms (psychosis, depression, etc.). Because papers published in the 1980s would have been reporting studies launched in the late 1970s, mostly using neither explicit diagnostic criteria nor established diagnostic instruments, we decided to limit further searches to the years 1990 to 2004 (exceptions see below). The literature and reference search was repeatedly updated for that time frame during the study period of July 2003 and July 2004. This search process 
(1990-2004) revealed initially over 3900 hits. Each of these hits was cross-checked and evaluated. The overwhelming majority of papers could be excluded immediately because no relevant prevalence data were reported in the publication. To be included in the systematic review and the subsequent analyses, the following criteria needed to be met:

1. Conducted in an EU country (including Iceland, Norway and Switzerland; total number of European countries included: 28).

2. Use of a population-based approach (i.e. subjects sampled from a defined community or the whole country).

3. Use of explicit diagnostic information according to established diagnostic criteria (by use of an established diagnostic instrument according to either ICD-9/ICD-10 or DSM-III-R/ DSM-IV. Diagnostic information should be assessed with one of the following diagnostic instruments: DIS (Robins et al., 1981), CIDI (Robins et al., 1988) and variants thereof, SCAN (Wing et al., 1990) or related approaches. We did not include studies assessing psychopathology and mental health exclusively by means of questionnaires or screening instruments (e.g. GHQ, Goldberg and Hillier, 1979; CIDI-SF, Kessler et al., 1998; MHI-5, Berwick et al., 1991). Diagnostic prevalence findings should refer to the past 12 months, although shorter intervals were also considered.

4. The scope of diagnoses covered by this review was mainly driven by their public health significance as well as the availability of respective data. The following diagnostic groups were considered (brackets indicate ICD-10 F-Codes of roughly equivalent terms): substance use disorders: alcohol dependence (F10.2x), illicit substance dependence (F1x.2x); psychotic disorders: schizophrenia (F20.xx), other psychotic disorders (F22.0, F23.xx, F29); mood (affective) disorders: major depression (F32.xx, F33.xx), dysthymia (F34.1), bipolar I or II (F31.xx); anxiety disorders: panic disorder with or without agoraphobia (F41.0/F41.01), agoraphobia without history of panic disorder (F41.00), generalized anxiety disorder (GAD, F41.1), social phobia (F40.1), any specific phobia (F40.2), obsessive-compulsive disorder (OCD, F42.x); somatoform disorders: somatization disorder (F45.0), undifferentiated somatization disorder (F45.1), pain disorder (F45.4), hypochondriasis (F45.2); eating disorders: anorexia nervosa (F50.0), bulimia nervosa (F50.2), atypical anorexia/bulimia (F50.9).

5. Age group covered: In the course of the search process it was also decided to limit the analyses to studies on subjects from 18 to 65 years old. The choice of this narrow age range was mainly determined by methodological considerations. Studies in children and young adolescents as well as those in the older people include considerably different assessment instruments, which makes it difficult to compare findings from studies in this age group with those in other age groups. Furthermore, reliability and validity for most diagnostic assessment instruments like the DIS and CIDI are only established for the age range from 18 to 65 years and might for example under-estimate prevalences in older individuals (Knäuper and Wittchen, 1994). Additionally, patterns of disability, burden, treatment, etc. might have different meanings and implications in these age groups.

6. Other data sources: Aside from community studies, we also identified some studies that provide information on the prevalence in primary care settings, as well as recognition and treatment rates. These studies typically focus on one or two target diagnoses in unselected primary care populations. They mostly refer to cross-sectional 2- week or 1-month diagnoses, rarely using established diagnostic instruments. Although primary care studies can provide 
important additional information, we decided to give priority to the population-based approach and do not report findings of these studies here. We also received some data from nationwide and registers of services (e.g. Belgium, Denmark, Poland, Portugal). However, because of the extremely high variability in diagnostic standards and reporting conventions of the register information, we felt unable to aggregate such data in a meaningful statistical way. Service register data are problematic for our purpose because they rely only on identified patients, whereas it has long been known that people with mental or psychiatric disorders often do not seek treatment or do not present their mental health problems as the reason for consultation and are therefore not identified as cases (Goldberg and Huxley, 1980).

\subsection{Structured country-specific expert consultations}

During the iterative search process, we personally contacted numerous European experts or expert groups involved in similar European cross-national projects (e.g., European Mental Health Status project; a complete list is available on http://www.ebc-eurobrain.net). These contacts were meant to ensure that no study was missed as well as to clarify whether significant information might be obtained by using unpublished data from ongoing or unpublished surveys.

In the process of assembling the studies and analysing the findings of these studies we established contact (structured personal or telephone interview) with at least one expert from each EU country. The role of these country-specific experts was generally to provide advice and guidance as well as to assist in clarifying questions like (a) Is the list of studies comprehensive and appropriate? (b) Are there additional studies in regions or the whole country not yet included (e.g. only reports, not published in an accessible journal)? (c) Is the interpretation that has been extracted from the material provided correct and comprehensive? The outcome of this consultation process was repeatedly compiled in revised tables and was circulated again to all experts. $\mathrm{N}=17$ expert inquiries were completed; besides confirmation of the studies we had found through electronic literature search, these inquiries identified additional 10 studies from the 27 studies reported below. Despite considerable attempts we failed to reach experts from the following countries: Cyprus, Estonia, Greece, Ireland, Latvia, Lithuania, Luxembourg, Malta, Slovakia and Slovenia. Furthermore, according to literature review and expert statements, no populationbased prevalence information could be provided for Poland and Portugal.

\subsection{Reanalyses of existing epidemiological data sets and credibility rating by country-specific experts}

As some publications and reports did not contain the prevalence data in the way we needed them for the survey, we accessed (with permission of the respective authors) the original data of the following studies: the Netherlands Mental Health Survey and Incidence Study (NEMESIS; Bijl et al., 1998), some of the countries participating in the ESEMeD project (ESEMeD/MHEDEA 2000 Investigators, 2002), the Mental Health Supplement of the German National Health Interview and Examination Survey (GHSMHS; Jacobi et al., 2002; Wittchen et al., 2000), and a study from Norway (OsLof study, unpublished data provided by I. Sandanger). These studies provide nationwide estimates in fairly powerful community samples for a wide range of disorders with the use of almost identical methods (variants of the CIDI). They further allow for a more detailed tabulation of findings (including 95\% confidence intervals) by disorder, total prevalence, gender and age groups (18-34, 35-49, 5065 ) as well as by other indicators such as impairment and disability or treatment rates (Bijl et 
al., 2003). These studies and the respective analyses were also used as a preliminary yardstick for the systematic expert inquiry.

These diagnostic and overall findings (by age group and gender) from the reanalyses were than submitted to the country-specific experts, regardless of whether any data or findings had been reported from that country. Each expert was requested to review these tables and to answer the following questions: „According to your expert knowledge or available study findings in your country, are the prevalence estimates in the table a) Fin the range of the respective 95\% confidence interval_, b) Fhigher_ (= above the upper limit of the confidence interval) or Flower_ (below the lower limit)?“ Experts were encouraged to indicate the „don’t know" category if they were not aware of any information about the prevalence of this diagnosis in their country. If the experts indicated higher or lower values, they were asked to explain and justify their rating, for example by providing a reference publication or data.

\subsection{Conventions and statistical procedures}

As the most common denominator available, 12-month prevalence estimates will be reported preferably as the most frequently used time frame across studies. For a few studies, only point prevalences were available; in these cases, we projected the point prevalence rates to a 12month estimate, using extrapolations from studies where both point and 12-month prevalences were available. The aggregation of diagnostic findings across all EU states was done mainly by reporting median percentage and interquartile range. Weighting schemes were examined as well but the unweighted findings will be presented. Data on prevalence distributions by age and gender, the respective 95\% confidence intervals (CI) as well as the estimates for „any mental disorder" were calculated from a study covering all diagnoses (GHS-MHS). To estimate the total number of people affected by the mental disorders under study in the 28 countries, the country-specific prevalences were multiplied by the most recent respective population sizes in the age range of 18-65 years (1st January 2003) retrieved via EUROSTAT (EUROSTAT, 2004). The total population of the countries under study is 465 million and 302 million, respectively, for the age 18-65. The median of all available studies was used as prevalence estimate for countries with no prevalence information. This estimate was supplemented by a lower (missing data replaced by the lower quartile of all available prevalence data) and an upper limit (missing data replaced by the upper quartile of all available prevalence data); these „confidence intervals“ are based on the assumption that the prevalence of mental disorders in countries with missing data lies within the interquartile range of all available studies.

\section{Results}

\subsection{Availability of epidemiological studies in the EU}

Table 1 lists 24 country-specific (combined $\mathrm{N}>70,000$ subjects) and three cross-national (combined $N>100,000$ subjects) community studies meeting the inclusion criteria. In the following sections, these studies are referred to by a study number in square brackets; note: the sites from the crossnational ESEMeD project [25] are treated as three separate studies here [25a, 25b, 25c]. Along with a core reference publication for each study listed, the table also provides information about country, fieldwork period, sample size and age range, diagnostic instruments used and types of mental disorders covered. Not all study findings could be used for our subsequent statistical modelling; in these cases, the diagnostic column is printed in italics. Reasons for not considering studies in subsequent reanalyses were the following: a) only lifetime prevalence available [1, 2, 21], b) restricted study population $[7,8,13]$ or c) 
other methodological problems (e.g. diagnostic algorithms or sampling procedures) [17, 27, 24].

Overall, the table indicates that some countries have been more active than others, e.g. Germany (6 studies), The Netherlands (4 studies) and the UK (5 studies). No populationbased data at all were available from 12 out of the 28 countries (Cyprus, Estonia, Greece, Ireland, Latvia, Lithuania, Luxembourg, Malta, Poland, Portugal, Slovakia, Slovenia), representing 54.8 million inhabitants (17.5\%) in the age range under study in the EU and Iceland, Norway and Switzerland (EUROSTAT, 2004). Thus, we use databased information from 21 studies covering 16 out of the included 28 European countries (representing roughly $80 \%$ of the population).

Sample sizes vary considerably between studies from $N=250$ to $N>10,000$ subjects. Age ranges studied are fairly consistent, although some studies have reported data only for a quite restricted age range (e.g. [8]: 18-24, [5]: > 30). The most frequently used diagnostic instrument (16 out of 27) across all studies is the Composite International Diagnostic Interview (CIDI; WHO, 1978; Wittchen, 1994; Wittchen et al., 1998a) or variants thereof (DIS, DISSI, MCIDI; Wittchen et al., 2001). This standardized diagnostic instrument does not require clinicians, but can be administered by trained non-clinicians as well. Other instruments used were the Schedules for Clinical Assessment in Neuropsychiatry (SCAN; Wing et al., 1990; four studies) and Mini International Neuropsychiatric Interview (MINI; Sheehan et al., 1998; two studies), both requiring clinically trained interviewers. Most of the studies are cross-sectional prevalence studies, although some also include follow-up components allowing the indication of incidence rates [7, 8, 16, 22].

There is considerable variation with regard to the spectrum of diagnoses covered in each study. Seven studies only examined one or two groups of mental disorders, frequently limiting themselves to depressive disorders or syndromes. Findings with such a restricted diagnostic range need to be treated with caution, because their ability to consider diagnostic exclusions in necessary detail is limited. This is a particularly critical issue in studies that claim to assess major depression in the absence of any module to exclude hypomania and mania. The majority of the studies cover at least several disorders. The most frequently studied diagnostic classes are depressive disorders, alcohol dependence and various forms of anxiety disorders. However, the fact that studies vary with regard to the detail they cover (e.g., various forms of anxiety disorders), makes it difficult to analyse aggregated prevalences of anxiety disorders in general. Less frequently studied are eating, somatoform, bipolar, psychotic and illicit substance use disorders.

\subsection{2-month prevalence by disorder across studies}

Fig. 1 presents the diagnostic prevalence findings of all eligible studies indicating the median, as well as distribution of the specific study findings by diagnostic group. Studies included for this graph are identified below in Table 2 (right column) with their study numbers according to Table 1; studies are sorted in ascending order of their prevalence estimates. Additionally, Table 2 shows the number of subjects and the number of studies by diagnosis used in Fig. 1, and the median and the interquartile range for each diagnosis.

The three most prevalent specific 12-month diagnoses among subjects from 18 to 65 years of age were major depression ( $\mathrm{Md}=6.9 \%)$, specific phobias $(\mathrm{Md}=6.6 \%)$ and somatoform disorders $(\mathrm{Md}=6.3 \%)$. The least prevalent conditions were eating disorders ( $\mathrm{Md}=0.4 \%)$, illicit 
drug dependence $(\mathrm{Md}=0.5 \%)$, obsessive-compulsive disorder $(\mathrm{Md}=0.7 \%)$ and psychotic disorders $(\mathrm{Md}=0.8 \%)$.

Fig. 1 reveals some variability in findings for depression, phobias, somatoform disorders and alcohol dependence, whereas estimates of other disorders appear to be relatively consistent.

For major depression (17 studies) estimates range between 3.1\% and 10.1\%; the density of findings around the median (6.9\%) [26, 25b, 11, 18, 20] is, however, remarkable. The second most prevalent diagnosis ( $\mathrm{Md}=6.4 \%$ ) is specific phobia, varying from a low of $0.8 \%$ [14] to a high of $11.1 \%$ [18]. This variation is apparently due to methodological factors. Studies with low estimates have assessed only a quite restricted range of specific phobias, or used some sort of exclusion hierarchy $[14,25]$, whereas the potential effect of impairment criteria is less evident. In contrast, studies based on instruments that specifically prompt for and examine the presence of all specific types of phobias (e.g. animal, situational, blood/injection/injury phobias) and strictly following DSM-IV criteria show consistently higher values. Similarly, the variability of somatoform disorders appears to be simply an artefact of the diagnostic coverage. Somatization disorder as the most severe form of somatoform disorders reveals consistent prevalence findings of $1.1 \%$ and $2.1 \%$ [14, 18]. Higher prevalences have been exclusively reported from studies that assessed a wider range of somatoform conditions. Among these, particularly pain disorders account for the high 12-month total rates in some of the studies $[8,9,10,19]$.

Alcohol dependence estimates vary from less than $0.5 \%$ [25a, 25c, 14, 3] to over $6 \%[20,18]$. These differences are apparent even between studies that used similar variants of diagnostic instruments (e.g. CIDI). A closer inspection reveals that variants of the CIDI obviously use different diagnostic algorithms for dependence, accounting probably for these large differences. In some lower estimate studies dependence was diagnosed only if the full dependence syndrome (3+ criteria) was currently present, whereas in higher estimate studies a diagnosis was also assigned to subjects currently meeting only partial criteria, but having met full criteria in the past. For drug dependence, fairly convergent low estimates were found. In interpreting this finding, it should be noted that this disorder is considerably more frequent (2-4 times) in adolescents and young adults (up to age 30), but rare in older persons; in addition, it remains unclear whether dependence of prescribed sedatives or other drugs has been assessed with sufficient integrity in the surveys covered (Rehm et al., 2005).

Anxiety disorders as a whole are clearly the largest diagnostic group and reveal by and large fairly consistent findings, except for specific phobias (see above). For social phobia $(\mathrm{Md}=2.3 \%)$, most studies cluster around the median [14, 10, 25a, 25b, 19], with three studies having lower [25c, 5, 9] and one study having very high [18: 7.9\%] estimates. The estimates for panic disorder ( $\mathrm{Md}=1.8 \%)$, agoraphobia $(\mathrm{Md}=1.3 \%)$ and $\mathrm{GAD}(\mathrm{Md}=1.7 \%)$ all reveal relatively narrow interquartile ranges.

The six studies on psychotic disorders $(\mathrm{Md}=0.8 \%)$ reveal some heterogeneity. This can be attributed to the fact that studies with higher prevalences $[14,10]$ refer not only to schizophrenia but to a wider range of psychotic syndromes (including mood incongruent syndromes in affective disorders), whereas those with lower prevalences refer to schizophrenic psychosis.

\subsection{2-month prevalence estimates by gender and age: expert ratings}


Table 3 provides a breakdown of prevalence estimates (with 95\% confidence intervals) by diagnostic group, single diagnoses and age and gender from study [10] as the diagnostically most comprehensive yardstick. Findings are presented along with the overall European median prevalence estimates from Fig. 1 and Table 2.

The two overall estimates are almost identical. Only for two diagnoses, namely psychotic and somatoform disorders, the $95 \%$ confidence interval and the interquartile range, respectively, do not overlap. The clear majority of experts believe that the „true“ prevalence of the disorder is in the range of the 95\% confidence interval indicated in Table 3. This applies to the rates reported for illicit substance use disorders, alcohol dependence, bipolar disorder, panic disorder, GAD, social phobia, specific phobias, OCD and eating disorders. More discrepancy resulted for the $2.6 \%$ (2.1-3.1) estimate of psychotic experiences and for the 12- month estimate of major depression of 8.3\% (7.4-9.2). A closer inspection revealed that the experts mainly rated the prevalence of schizophrenic psychosis, whereas the reference rate was related to psychotic syndromes of any type. In fact, if the stricter criteria for schizophrenic psychoses is applied to the $2.6 \%$ estimate of study [10], the rate drops to $0.9 \%$ (95\% CI: $0.7-$ 1.1), matching perfectly the experts' opinion.

For major depression no clear resolution emerged, although there seems to be some tendency that experts with experience in cross-sectional clinical interviews, such as the SCAN, tend to rate consistently lower depression prevalences than those working with non-clinician interviews, such as the CIDI in its variants. The table also reveals that the overall 12-month prevalence of having any alcohol, drug, psychotic affective, anxiety, somatoform or eating disorder is $27.4 \%$ (95\%CI: $26.0-28.9$ ), and $33.2 \%$ for women and $21.7 \%$ for men, respectively. Except for substance use disorders (men: 5.6\%, women: 1.3\%) and psychotic disorders (almost identical estimates), rates for women are approximately twice as high as compared to those for men. Anxiety (12.0\%, 95\% CI: 11.1-13.0), and somatoform disorders (11.0\%; 10.1-12.1) are the most frequent aggregated disorders, followed by mood (affective) disorders (9.1\%) and substance dependence (3.4\%). Note that there is a substantial degree of comorbidity: Among the cases with at least one mental disorder, $68 \%$ have only one, $18 \%$ have two, and 14\% have more than two 12-month diagnoses.

\subsection{Estimating the size of mental disorders: how many people are affected?}

On the basis of these 12-month estimates, Table 4 shows the estimated number of subjects summed up over all 28 countries (in millions, age 18-65, with lower and upper confidence intervals, depending on the handling of missing data) who met the diagnostic criteria for one or more mental disorder listed during the past 12 months.

The aggregate figure for „any mental disorder“ was estimated from GHS-MHS data because this was the only study covering all included diagnoses. $27.4 \%$ (82.7 million) fulfilled the criteria for at least one diagnosis. The prevalence of comorbidity was calculated according to the proportions of comorbid cases in the GHS-MHS: $68 \%$ of all cases had only one of the diagnoses under study (56.5 million), 18\% had two (15.0 million) and 14\% had three or more diagnoses (11.2 million).

\subsection{Disability}

The considerable heterogeneity in which impairments and disabilities were assessed and evaluated in the studies reviewed, as well as the very different conventions used to report findings, does not allow for joint analyses across studies. Despite this variability, the majority 
of studies relatively uniformly and independent of methods used [3, 5, 8, 9, 10, 14,16,17, 22, 25,26 ] provides at least some evidence that all mental disorders are associated with substantial levels of either disability or reduction in quality of life and that these measures increase by number of comorbid conditions. There are also strong indications that depressive disorders (major depression and dysthymia), and panic disorder rank among the disorders with strongest impact. However, such relative comparisons across studies need to be treated with caution because of the differences in diagnostic coverage as well as because of the inconsistency in which studies controlled for comorbidity. The only available cross-national and directly comparative data in this respect come from the ESEMeD study revealing that health-related quality of life (mental health score of the SF- 12, Ware et al., 1996) was reduced by approximately 1.0 standard deviation units in most mental disorders. Further, most disorders were associated with a loss of three times more work days (WLD) compared to having no 12-month mental disorder (ESEMeD/MHEDEA 2000 investigators, 2004b). Neurological disorders (22\% workdays lost during past 30 days) were found to have the strongest WLD impact, followed by panic disorder, specific phobias, and posttraumatic stress disorder (all 11\%), depressive disorder (9\%) and social phobia (8\%). Alcohol abuse/dependence, in contrast, revealed lower values (3\%). Using identical measures in the aggregate six-country-comparison, we found mental disorders usually to reveal a stronger WLD association than many somatic disorders (e.g. diabetes: 2\% WLD loss, lung disease: 4\%, heart disease: $7 \%$ ).

\subsection{Health care utilization and treatment}

Some of the studies reviewed have analysed utilization and treatment issues in greater detail $[6,8,10,14,16,22,23,25,26]$. Almost all remaining studies reviewed made some statements about treatment and agreed that only a small fraction of all cases with mental disorder receive some treatment. Nevertheless, the inconsistency with which this group of variables is addressed (type and content of questions, time frame, level of detail, national characteristics, etc.) prohibits any systematic analyses across countries or even crude metaanalytic approaches. In this respect, there are, however, two noteworthy exceptions: Bijl et al. (2003) compared in a reanalyses the proportions of treated cases with any mood or anxiety disorder in Germany [10] and the Netherlands [16]. Their analysis revealed relatively similar findings despite considerable differences in the health care systems. In both countries, only $13 \%$ to $20 \%$ of all cases with a mental disorder have received some form of treatment during the past 12 months. They also demonstrated that treatment rates in both countries are strongly related to severity (measured by degree of disability) with $67 \%$ of the most serious mental disorders being treated in both countries. However, the study also highlighted remarkable differences between countries in terms of access of use, utilization rates, as well as care sector. In The Netherlands, for instance, the majority of cases received treatment in the primary care sector (74\%) and $48.5 \%$ received speciality treatment, whereas Germany had higher specialist care (70\%) and lower primary care rates (39\%). More comprehensive analyses pointing in the same direction are available as part of the ESEMeD study [25] (Table 5). Covering six countries and using a wider definition for mental health consultation than did previous studies, they found that $25.7 \%$ of all cases with mental disorders reported formal health care consultations for mental health reasons in the past month. Consultation rates were higher among those with comorbidity (40\%) and highest among those with mood disorders (36.5\%). In general, one third of all consultations were made in primary care only, one third with mental health specialists (psychiatrist, psychologist, counselor) and a further third with other professionals. As shown in Table 5, drug treatment was the most frequent form of treatment provided. 


\section{Discussion}

The survey identified overall a remarkable total of 27 recent epidemiological studies in the community that included over 155,000 subjects from 16 European countries. Across all these studies it is estimated that $27 \%$ of the adult (18-65 years of age) EU population (including Iceland, Norway and Switzerland) suffer from at least one mental disorder. This 12-month prevalence estimate equals an estimated total of 82.7 million subjects affected. Lifetime incidence data, available from some of these studies suggest also that almost every second person in the EU is or has been affected by mental disorders at some point in lifetime. Despite considerable variability in methods and designs, there is further agreement across all studies for higher rates in women as opposed to men (33\% vs. 22\%), and almost equally high prevalences across all age groups as well as a considerable degree of comorbidity. There is also agreement across studies about the disabling nature of mental disorders. Many mental disorders, in particular anxiety, substance and somatoform disorders, start as early as in childhood, having typically adverse effects on the further neurocognitive development, such as with regard to school and academic achievement, social functioning and social integration, that might persist throughout the lifespan. Fairly independent of country and type of study, the review also reveals that in general mental disorders are poorly recognized and diagnosed in health care institutions and rarely receive specific mental health treatments.

Before discussing these findings in greater detail, several limitations need to be acknowledged. (i) To estimate the total prevalence of mental disorders in Europe, we included studies that were partly very different with regard to diagnostic scope and instruments, sampling methods, age group targeted, field work techniques, diagnostic algorithms and the categories and overall statistical analysis. (ii) Although we tried to account for such effects, our prevalence findings and total EU population estimates calculated across studies should be taken with caution, especially because for 12 countries no population-based data were available at all (Cyprus, Estonia, Greece, Ireland, Latvia, Lithuania, Luxembourg, Malta, Poland, Portugal, Slovakia, Slovenia). These countries represent 54.8 million inhabitants (i.e. $17.5 \%$ of the total EU population) in the age range under study in the EU and Iceland, Norway and Switzerland (EUROSTAT, 2004). Our assumption that the prevalence estimates from some EU countries can be generalized to other EU countries is questionable and thus requires future examination. (ii) Another important limitation is the restriction on adults, namely adults in the age range 18-65. The relatively few studies in children and adolescents as well as studies in older persons (65+ years of age) were excluded in order to avoid additional heterogeneity as well as reliability and validity problems with regard to diagnostic classes and instruments (Wittchen et al., 2003). (iii) The findings rely entirely on 12-month prevalence estimates and a restricted coverage of diagnoses. The limitation to prevalence studies was due to the almost complete lack of age-adjusted incidence findings for most groups. (iv) Because all studies used a different diagnostic spectrum, it was not possible to calculate overall rates of „any mental disorder“ or overall rates for patterns of comorbidity. Instead, we calculated overall and comorbidity rates, using the diagnostically most comprehensive study as a yardstick. Thus these rates should be interpreted with caution. (v) The reliability and validity and cross-national consistency of diagnostic instruments for mental disorders has not been sufficiently established.

Within the context of these limitations, we can conclude that

(1) there is a remarkable number of prevalence studies from community samples in the EU. These studies, however, were mostly national or regional studies; cross-national studies were quite rare. From the total spectrum of several hundreds of diagnoses of mental disorders, the 
most frequent diagnoses were anxiety, mood (affective) and substance dependence disorders. Less frequently, psychotic, somatoform and eating disorders were investigated. Consistent with the international situation and other inquiries (e.g. Kessler et al., 1994; Fryers et al., 2004), almost no community studies with established explicit diagnostic criteria were identified with regard to other mental disorders such as sleep disorders, impulse control disorders, personality disorders, etc.

(2) Despite a high degree of study variability with regard to sampling, design and instrumentation, there is a considerable degree of convergence in the 12-month prevalence findings across the mostly completely independent studies. Furthermore, the findings from the studies reviewed appear to be relatively similar to those obtained in other countries outside the EU (i.e. Andrade et al., 2000; Weissman et al., 1992, 1994, 1996, 1997): When accounting for design, sampling and other methodological differences between studies, little evidence seems to exist for pronounced cultural or between-country variation. However, it must be acknowledged that none of the studies reviewed was designed and powered to detect cultural differences in the expression of various types of mental disorders, for example with regard to onset, course, complications and symptom profiles.

(3) On the basis of meta-analytic techniques as well as reanalyses of selected data sets, we estimated that about $27 \%$ of the adult EU population 18-65 years old are or have been affected by at least one mental disorder in the past 12 months. In population terms, it is estimated that between 78.5 and 87.1 , or roughly 82.7 million, are affected. The estimate could be regarded as a quite conservative estimate because of the following reasons: a) Only some of the many mental disorder were considered. b) This estimate does not include older persons (65+ years) as well as c) adolescents (14-17 years), for whom even higher estimates are established (Wittchen et al., 1998b).

(4) Quantitatively and in accordance with most other recent international comparison studies (i.e. Andrade et al., 2000; Merikangas et al., 1998; Weissman et al., 1996, 1997; Wittchen, 1994), anxiety disorders rank as the most frequent (12-month prevalence median: 12\%; 36.3 million subjects affected) group of disorder, followed by mood disorders (major depression and bipolar disorder: 7.8\%; 20.8 million), somatoform disorders (persistent pain, hypochondriasis and somatization disorder: 6.3\%; 18.9 million), substance dependence (3.4\%; 9.2 million) and psychotic disorders ( $0.8 \%$; 3.7 million). The partly considerable variations in prevalence estimates even between studies using similar instruments seem to be a result of many factors: different scope of diagnoses covered, different impairment criteria, technical differences in the diagnostic algorithm and skip rule handling (WHO-World Mental Health Consortium, 2004). Studies like ESEMeD (2004) also include a considerable proportion of the population older than 65 . For the older group, however, diminished reliability and validity findings were shown, resulting in artificially low prevalences for anxiety and depression (Knäuper and Wittchen, 1994). Because of the different service needs and differences in impairment and disability we made special attempts to provide also information about a broader spectrum of mental disorders than did previous studies. The indication of rates for bipolar I (presence of manic episode) and bipolar II (Hypomania) disorders ( $\mathrm{Md}=0.9 \%)$, specific types of anxiety disorders, obsessive-compulsive disorder (0.7\%), somatoform disorders $(\mathrm{Md}=6.3 \%)$ or eating disorders $(\mathrm{Md}=0.4 \%)$ rarely considered in surveys outside Europe is a particular strength of the study.

(5) Although most of the studies reviewed point to the phenomenon of comorbidity, it was unfortunately not possible to compute specific comorbidity patterns across studies, because studies differed largely as with regard to the diagnoses covered. Consistent with the Kessler et 
al. (1994) we found that almost every second case with a mental disorder had more than one diagnosis and that approximately $30-40 \%$ of all subjects suffering from an anxiety disorder also had a depressive disorder and vice versa.

(6) For the issue of disability, almost all of the studies reviewed made - partly substantial contributions. However, the heterogeneity of methods, assessments and analyses did not permit a systematic analysis of findings. The available data though from three available coordinated cross-national studies (ESEMeD/ MHEDEA 2000 Investigators, 2004b; Bijl et al., 2003; Jacobi et al., 2004a,b) confirm the immense disability burden in terms of several crude (years lived with disability, work loss days, etc.) and more sophisticated indicators (work productivity, quality of life, etc.). Consistent with numerous earlier studies for specific diagnoses (Bijl and Ravelli, 2000a; Jacobi et al., 2004b; Greenberg et al., 1996, 1999; Kessler and Frank, 1997; Rice and Miller, 1998; Spijker et al., 2004; Wittchen, 2002) and expertbased WHO projections (i.e. Murray and Lopez, 1996; Olesen and Leonardi, 2003), there is thus little doubt that mental disorders rank together as the quantitatively most disabling group of all medical disorders. These data, despite some diagnosis-specific differences, highlight a substantial degree of functional disability and overall burden, even for seemingly „less serious“ disorders (Andlin-Sobocki et al., 2005). This is because of the critical combination of their high prevalence, the associated impairments and disabilities, the frequent early onset as early as in childhood or adolescence and the substantial degree of persistence and comorbidity over the life-span (Fehm et al., 2005).

(7) Health care utilization and treatment data: In sharp contrast to the needs of health care researchers and politicians, the considerable heterogeneity of assessment strategy and the lack of detail make it almost impossible to make joint analyses for utilization and treatment. The availability of the six-country study ESEMeD/MHEDEA 2000 (2004c) provides, however, some benchmark data, that appear by and large consistent with several individual national and regional studies (Bijl and Ravelli, 2000b; Bijl et al., 2003; Jacobi et al., 2004a,b; ten Have et al., 2004; Wittchen, 2000). According to these convergent findings, only one out of two patients with a mental disorder has ever received some professional attention. Among those with at least one contact, the vast majority is seen only in primary care. There is little doubt that only about one out of four of all subjects with mental disorders receive any professional help and even fewer receive grossly adequate (10\%) mental health care through drugs or psychotherapy. Even in the more comprehensive health care systems with access even to psychotherapy free of charge, such as Germany (Jacobi et al., 2004a,b), the situation is not markedly different. Thus we can conclude that across the EU there seems to be substantial degree of unmet needs for treatment. There are some indications that the type and degree of unmet needs vary widely by type of region and country (ESEMeD/MHEDEA 2000 Investigators, 2004c) and that only some disorders, such as depression are more likely to receive any professional attention and treatment (Bijl et al., 2003).

To conclude, the results of this EU review are overall consistent with those of earlier international studies and reveals little indications for a generally better mental health of either one country over another as has been suggested in a recent publication (The WHO World Mental Health Survey Consortium, 2004; ESEMed/MHEDEA 2000 Investigators, 2004a). Mental disorders are diverse in their manifestations and affect about one third of the EU population during any given 12-month period, most of whom are not receiving any treatment.

Beyond these core findings (for disorder specific details see Berr et al., 2005; Fehm et al., 2005; Goodwin et al., 2005; Lieb et al., 2005; Paykel et al., 2005; Pini et al., 2005; Rehm et al., 2005a,b; Rössler et al., 2005; Von Campenhausen et al., 2005) and our attempt to estimate 
the size and burden with greater precision and validation than was done in the past, our findings also highlighted several evident future research needs:

1. There is a strong need for greater coordination and even standardisation of methods to improve the quality and comparability of epidemiological data in the EU. In general, Europe is characterized by an immense diversity of mostly national studies (single country or region) with a considerable degree of clinical and methodological sophistication. This „richness“, however, has the considerable disadvantage of restricting the possibility of direct comparisons between countries and estimating prevalence across all EU countries (Fryers et al., 2004).

2. There is a need of incidence studies especially in children and adolescent that would provide better guidance for the onset and natural course as well as the design of preventive trials and early interventions. This seems to be of particular relevance for secondary comorbidity, which might be prevented if earlier and rapid treatment of the primary disorder were applied.

3. There is also a strong need for studies in older persons that inform about the most prevalent mental disorders in old age, the patterns of comorbidity with neurological and other somatic conditions as well as specific needs of interventions in this age group.

4. As a diagnosis of mental disorder cannot be equated with specific treatment needs, there is a need for studies that allow the derivation of appropriate criteria. In light of the high prevalence of mental disorders in the community, it seems not feasible to deliver care to everybody. Thus clinically sensitive and economically feasible decision algorithms are needed to determine which type of interventions should be assigned to what type of patient. These algorithms might go beyond the established diagnostic classes acknowledging additionally patterns of comorbidity, behavioural, medical and developmental risks instead of oversimplified measures of current „severity“ or „impairment“.

5. There is a continued need of descriptive studies informing us in greater detail to what degree mental disorders are appropriately recognized and treated in the various European health care systems. Such studies should allow comparisons across Europe, but should additionally be optimally designed according to the respective national health care system to provide the type of data most useful for the particular country. Such data are likely to be instrumental in the designation of more appropriate and more effective health care delivery infrastructure.

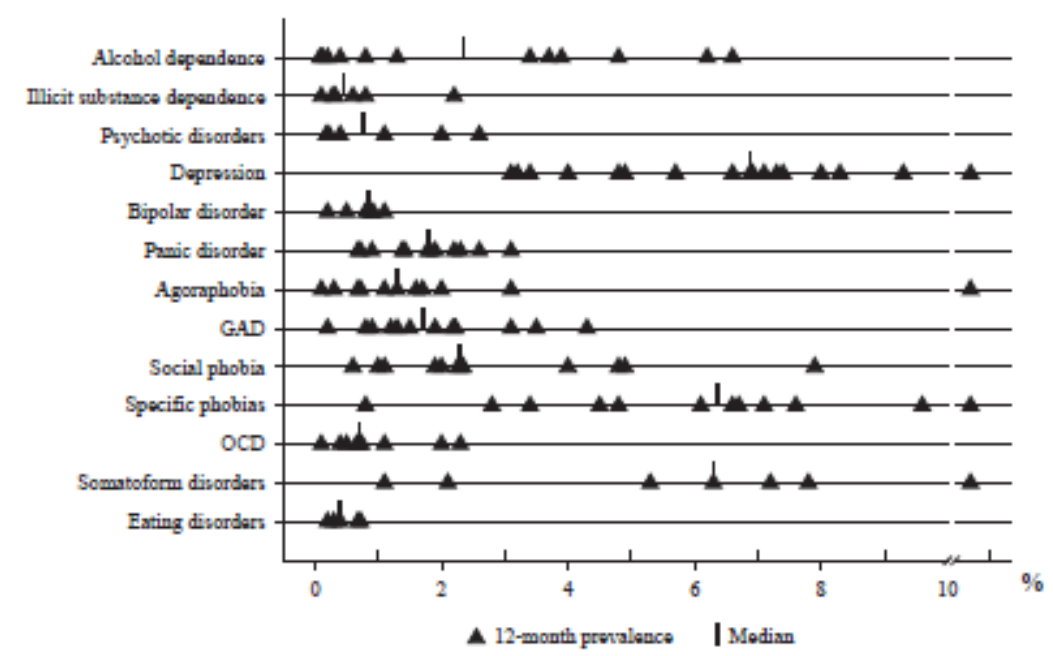

Fig. 1. Distribution and medians of publishal European 12 -month prevalence estimales of mental disorders. 
Table 1

Population based European studies on the epidemiology of mental disonders (after 1990)

\begin{tabular}{|c|c|c|c|c|c|c|c|}
\hline No. & Country & Study & Time of fieldwork & $N$ (age) & $\begin{array}{l}\text { Diagnostic instruments } \\
\text { (sysiem/criteria) }\end{array}$ & Disorders ${ }^{n}$ & Prevalence publications \\
\hline 1 & $\begin{array}{l}\text { Belgium, Provience de } \\
\text { Liegede Luxembourg }\end{array}$ & & 1997 & $1244(18-54)$ & $\begin{array}{l}\text { CIDI } 2.1 \\
\text { (DSM-IV/ICD-10) }\end{array}$ & $\begin{array}{l}A L C, D R U G, M D, B M P \\
O C D, P T S D, P D, G A D, \\
\text { photias }\end{array}$ & Ansesu (1999) \\
\hline 2 & Belgum, Liège & $\begin{array}{l}\text { Quality of Life and } \\
\text { Health Study }\end{array}$ & 1990 & $250(25-45)$ & DISSI (DSM-III) & $\begin{array}{l}A L C, M D, B I P, G A D \\
\text { phobias, } O C D, S O M\end{array}$ & Baruffol (1993) \\
\hline 3 & Croch Republic & Crech CIDI Study & $1998-1999$ & $1497(18+)$ & $\begin{array}{l}\text { WHO-CIDI } \\
\text { (DSM-IV/ICD-10) }\end{array}$ & $\begin{array}{l}\text { ALC, PSYC, BP, SPP, } \\
\text { SOM+other CIDI } \\
\text { disonders not included } \\
\text { here }\end{array}$ & $\begin{array}{l}\text { unpublished } \\
\text { data from Dragomirecka, } \\
\text { Andrade et al. (2003) }\end{array}$ \\
\hline 4 & Dermark & & 2000 & $2040(20-79)$ & MDI (DSM-N/ACD-10) & MD & Olsen (2004) \\
\hline 5 & Finland & The Health 2000 Study & $2000 / 2001$ & $6005(>30)$ & M-CIDI (DSM-IV) & $\begin{array}{l}\text { ALC, MD, PD, AG, } \\
\text { GAD, SOC }\end{array}$ & Pirkola et al. (2005) \\
\hline 6 & Finland & $\begin{array}{l}\text { Part of the Finnidh } \\
\text { Health Care Survey }\end{array}$ & 1996 & $5.993(15-75)$ & $\begin{array}{l}\text { UM-CIDLShort Form } \\
\text { (DSM-II-R) }\end{array}$ & MD & Lindeman et al. (2000) \\
\hline 7 & Germany, Dresden & Dresden Study & $1996-1999$ & $\begin{array}{l}1543 \text { (wamen, } \\
18-24 \text { ) }\end{array}$ & DIPS (DSM-IV) & $\begin{array}{l}A L C, D R U G, P S Y C \\
M D, B I P, P D, A G, S O C \\
G A D, S P P, P T S D \\
O C D, S O M, E A T\end{array}$ & Becker et al. (2000) \\
\hline 8 & Gernany, Murich & $\begin{array}{l}\text { Early Devidopmental } \\
\text { Stages of Psychopsthology } \\
\text { Study (EDSP) }\end{array}$ & $1995-2004$ & $\begin{array}{l}3021 \text { (14-24 at } \\
\text { thaseline) }\end{array}$ & M-CIDI (DSM-IV) & $\begin{array}{l}A L C, D R U G, P S Y C, \\
M D, B I P, P D, A G, S O C \text {, } \\
G A D, S P P, P T S D, \\
O C D, S O M, E A T, \\
\text { childhood disarders and } \\
\text { others }\end{array}$ & $\begin{array}{l}\text { Witchen et al. (1998b), } \\
\text { Lieb et al. }(2000)\end{array}$ \\
\hline 9 & $\begin{array}{l}\text { Gernany, Schleswig } \\
\text { Holstein }\end{array}$ & $\begin{array}{l}\text { Transitions in Aloohol } \\
\text { Consurngtion and Smaking } \\
\text { (TACOS) }\end{array}$ & $1996-1997$ & $4075(18-64)$ & M-CIDI (DSM-IV) & $\begin{array}{l}\text { ALC, DRUG, MD, BP, } \\
\text { PD, AG, GAD, SOC, } \\
\text { SPP, OCD, SOM, EAT }\end{array}$ & $\begin{array}{l}\text { Meyer et al. }(2000 \text {, } \\
2001)\end{array}$ \\
\hline 10 & $\begin{array}{l}\text { Germanty, nstionally } \\
\text { representative }\end{array}$ & $\begin{array}{l}\text { Gernan National Health } \\
\text { Interview and Examination } \\
\text { Survey (GHS-MHS) }\end{array}$ & 1998-1999 & $4181(18-65)$ & M-CIDI (DSM-N) & $\begin{array}{l}\text { ALC, DRUG, PSYC, } \\
\text { MD, BIP, PD, AG, SOC, } \\
\text { GAD, SPP, OCD, SOM, } \\
\text { EAT }\end{array}$ & $\begin{array}{l}\text { boobi et al. (2002, } \\
\text { 2004a), Wittchen et al. } \\
(2000)\end{array}$ \\
\hline 11 & Hungary & & $1995 / 1996$ & $2953(18-64)$ & DIS & $\begin{array}{l}\text { MD, BIP, PD, AG, } \\
\text { GAD, SOC, SPP, OCD }\end{array}$ & $\begin{array}{l}\text { Rilmer et al. (2001), } \\
\text { Sradoczky et al. (1997, } \\
1998,2000,2002)\end{array}$ \\
\hline 12 & loeland & & 1987 & $775(16-75)$ & $\begin{array}{l}\text { postal questicnnaire } \\
\text { (DSM-II-R) }\end{array}$ & SOC, SPP, AG & Amarnon et al. (1998) \\
\hline 13 & loeland & & 1987/88 & $\begin{array}{l}862 \text { (all bom } \\
1931 \text { ) }\end{array}$ & $\begin{array}{l}\text { DIS (DSM-II// } \\
\text { DSM-m-R) }\end{array}$ & $\begin{array}{l}\text { ALC, DRUG, PSYC, } \\
M D, B P, P D, A G, S O C \text {, } \\
G A D, S P P, P T D, \\
O C D, S O M, E A T, \\
\text { cognitive inpuiment, } \\
\text { and athers }\end{array}$ & $\begin{array}{l}\text { Stefansson et al. (1991), } \\
\text { Lindal and Stefansson } \\
\text { (1993) }\end{array}$ \\
\hline 14 & Italy, Florence region & Sesto Fiorentino study & $2000 / 2001$ & $2363(14+)$ & $\begin{array}{l}\text { MINI FPI } \\
\text { (DSM-IV/ICD-10) }\end{array}$ & $\begin{array}{l}\text { ALC, PSYC, MD, PD, } \\
\text { AG, GAD, SOC, } \\
\text { SPP,OCD, SOM, EAT }\end{array}$ & Faravelli (2004) \\
\hline 15 & Italy & & 1998 & $3550(18+)$ & MINI (telemstic) & MD & Dubini et al. (2001) \\
\hline 16 & $\begin{array}{l}\text { Nethedands, nationally } \\
\text { regresentative }\end{array}$ & $\begin{array}{l}\text { Nethertands Mental Health } \\
\text { Survey and Incidence Study } \\
\text { (NEMESIS) }\end{array}$ & 1996 & $7076(18-64)$ & CIDI 1.1 (DSM-III-R) & $\begin{array}{l}\text { ALC, DRUG, PSYC, } \\
\text { MD, BIP, PD, AG, } \\
\text { GAD, SOC, SPP, OCD, } \\
\text { EAT }\end{array}$ & $\begin{array}{l}\text { Bij1 et al. }(1998) \text {, Bij1 } \\
\text { and Ravelli }(2000 \mathrm{a}, \mathrm{b})\end{array}$ \\
\hline 17 & $\begin{array}{l}\text { Nethetands, Soufh } \\
\text { Holland }\end{array}$ & Zuid-Holland Study & $1983-1997$ & $\begin{array}{l}2076 \text { (first wave; } \\
\text { age 11-19) }\end{array}$ & CIDI DIS & $\begin{array}{l}\text { ALC, DRUG, PSYC, } \\
M D, B P, P D, A G, S O C, \\
G A D, S P P, P T S D, \\
O C D, S O M, E A T, \\
\text { childhood disonders and } \\
\text { others }\end{array}$ & Hofstra et al. (2001) \\
\hline 18 & Narway, Osko & $\begin{array}{l}\text { Norwegian psychistric } \\
\text { epidemiological study }\end{array}$ & $1994-1997$ & $2066(18-65)$ & CIDI 1.1 (DSM-III-R) & $\begin{array}{l}\text { ALC, DRUG, PSYC, } \\
\text { MD, BIP, PD, AG, } \\
\text { GAD, SOC, SPP, OCD, } \\
\text { SOM, EAT }\end{array}$ & Kringlen et al. (2001) \\
\hline 19 & $\begin{array}{l}\text { Narway Oslo and } \\
\text { Lofoten }\end{array}$ & OsLof study & 2001 & $1691(18+)$ & $\begin{array}{l}\text { WHO-CIDI } 1.2 \\
\text { (DSM-IV/ICD-10) }\end{array}$ & $\begin{array}{l}\text { MD, PD, AG, GAD, } \\
\text { SOC, SPP, PISD, SOM }\end{array}$ & unpublished [Sandanger] \\
\hline 20 & Sweden, Skickholm & PART-Study & $1998-2001$ & $10,441(20-64)$ & $\begin{array}{l}\text { SCAN, version } 2.1 \\
\text { (+ oftere questionnaire } \\
\text { data) (DSM-IV) }\end{array}$ & $\begin{array}{l}\text { ALC, MD and wide } \\
\text { range of others }\end{array}$ & HElktröm et al. (2003) \\
\hline 21 & Switzorland, Basel & & $1988-1991$ & $470(18-65)$ & $\begin{array}{l}\text { CIDI } 1.0 \\
\text { (DSM-III-R/CD-10) }\end{array}$ & $\begin{array}{l}\text { antiety and depnessive } \\
\text { disanders }\end{array}$ & Wbcker (1995) \\
\hline 22 & Switzaland, Zurich & The Zurich Cohort Study & $1979-1999$ & $\begin{array}{l}591(21 / 22 \text { at } \\
\text { first wave) }\end{array}$ & $\begin{array}{l}\text { SPIKE (DSM-III/ } \\
\text { DSM-III-R; threshold } \\
\text { and subthreshold } \\
\text { disonters) }\end{array}$ & $\begin{array}{l}\text { antiefy, depnessive, } \\
\text { bipolat and ather } \\
\text { disanders, including } \\
\text { subthreshold condifions, } \\
\text { OCD }\end{array}$ & $\begin{array}{l}\text { Angst et al. (1984), } \\
\text { Angst et al. (2004) }\end{array}$ \\
\hline
\end{tabular}




\begin{tabular}{|c|c|c|c|c|c|c|c|}
\hline$\overline{\text { No. }}$ & Counity & Study & Time of fieldwark & $N$ (age) & $\begin{array}{l}\text { Disgnostic instruments } \\
\text { (system/criteria) }\end{array}$ & Disanders" & Prevalence publications \\
\hline 23 & $\begin{array}{l}\text { UK, nationally } \\
\text { representiative }\end{array}$ & $\begin{array}{l}\text { OPCS UK Houschold } \\
\text { survey }\end{array}$ & $\begin{array}{l}\text { 1993/1994 repeat } \\
\text { survey: } 2000\end{array}$ & $\begin{array}{l}10,108(16-64) \\
\text { repeat survey: } \\
8886(16-74)\end{array}$ & CIS-R SCAN (ICD-10) & $\begin{array}{l}\text { ALC, DRUG, PSYC, } \\
\text { MD, PD, GAD, OCD } \\
\text { and others }\end{array}$ & $\begin{array}{l}\text { Jenkins et al. (1997a,b), } \\
\text { Meltzer et al. ( } 1995) \text {, } \\
\text { repeat survey: Singletcon } \\
\text { et al. (2001) }\end{array}$ \\
\hline 24 & $\begin{array}{l}\text { UK, Nothem Ireland } \\
\text { (District of Derry) }\end{array}$ & $\begin{array}{l}\text { Population study in the } \\
\text { District of Derry }\end{array}$ & $1993-1994$ & $\begin{array}{l}1242 \text { (GHQk } 923 \\
\text { (SCAN) (18-64) }\end{array}$ & $\begin{array}{l}\text { GHQ-28 SCAN } \\
\text { (ICD-10) }\end{array}$ & $\begin{array}{l}A L C, D R U G, P S Y C, \\
M D, P D, A G, G A D, \\
S P P, P T S D, O C D, \\
\text { adyusment disonders }\end{array}$ & Moconnell et al. $(2002)$ \\
\hline \multicolumn{8}{|c|}{$\begin{array}{l}\text { cross-national } \\
\text { studies: }\end{array}$} \\
\hline 25 & $\begin{array}{l}\text { Belgium, Fance, } \\
\text { Germany, Italy, } \\
\text { Netherlands, } \\
\text { Spain }\end{array}$ & $\begin{array}{l}\text { ESEMeD (Eurconean Study } \\
\text { of the Eqidemiology } \\
\text { of Mential Disorders) }\end{array}$ & $2001-2002$ & $21,425(18+)$ & CIDI (DSM-IV/ACD-10) & $\begin{array}{l}\text { ALC, MD, GAD, SPP, } \\
\text { PD, AG, SOC, OCD }\end{array}$ & 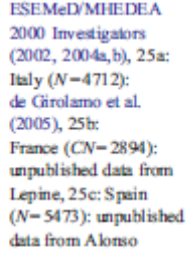 \\
\hline 26 & $\begin{array}{l}\text { Belgium, Fance, } \\
\text { Germany, Netherlands, } \\
\text { Spain, UK }\end{array}$ & DEPRESDEPRES 2 & 1995 & $\begin{array}{l}78,463 \text { (screening } \\
18+\text { ) }\end{array}$ & $\begin{array}{l}\text { MINI DEPRES 2: } \\
\text { questionnaire }\end{array}$ & MD & $\begin{array}{l}\text { Lepine et al. (1997), } \\
\text { Angst et al. (2002), } \\
\text { Tylee et al. (1999a,b) }\end{array}$ \\
\hline 27 & $\begin{array}{l}\text { Liverpool (UK), Dublin } \\
\text { (Ireland), Osko } \\
\text { (Narway), Turku } \\
\text { (Finland), Santander } \\
\text { (Spain), one rural and } \\
\text { one urtan setting each }\end{array}$ & ODIN & $1996-1998$ & $8862(18-64)$ & $\begin{array}{l}\text { fint phase: BDI second } \\
\text { SCAN }\end{array}$ & $\begin{array}{l}\text { deppressine disarders, } \\
\text { adjustsment disarder }\end{array}$ & $\begin{array}{l}\text { Ayuso-Mateos (2001), } \\
\text { Dowrick et al. (1998) }\end{array}$ \\
\hline
\end{tabular}

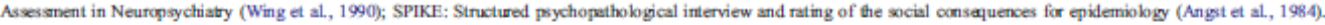

"ALC: abohol dependence, DRUG: illikit suhssance dependence, PSYC: any psychotic disorder, MD: major depresion, BIP: any bipolar disorder, PD: panic disorder with/without agoraphotia, AG:

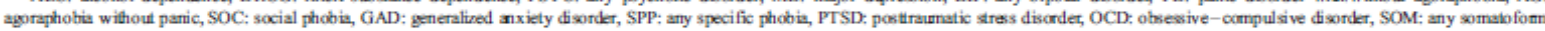
disorder, EAT: any eating disorder.

"If diagnoses are prinied in italies: results were not used in later analyses (Fig, 1, Tahle 2) due to time frame (anly lifetime prevalences available), restrided suly population (e.g. only young adults and adolescents) or otha methodological difficulties

Table 2

European prevalence rates for the last year across 21 studies (with a volal of $N=65,000$ satjects from national studies and $N-91,000$ subjects from crosnational studies)

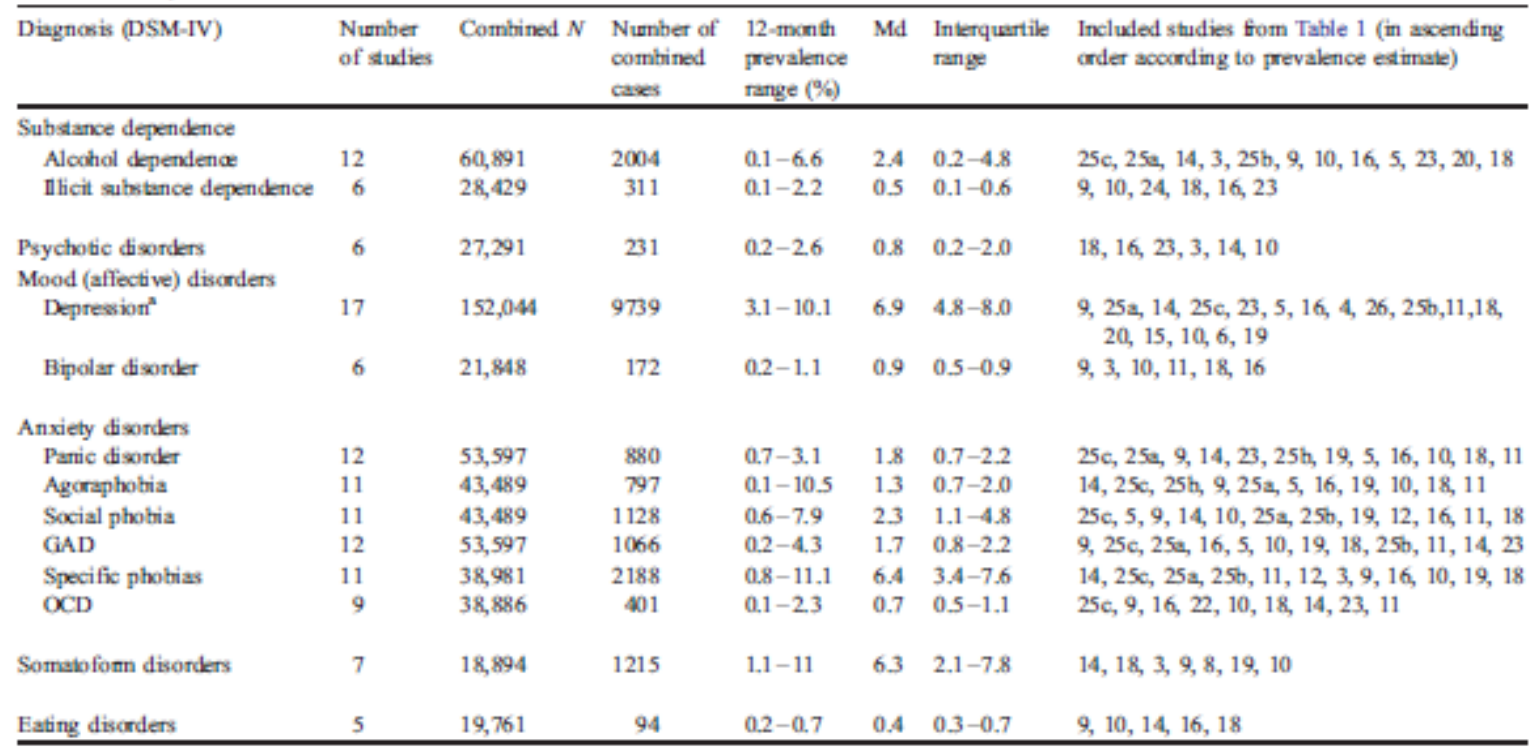

" heludes major depressive disorder, major depressive eqisode with and without diagnostic exclusions. 
Table 3

12-month prevalence of mental disorders by ags and sex in the commurity (age 18-65) [GHS MHS data], alcng with expert ratings for EU courtries, keeland, Norway and Swituertand

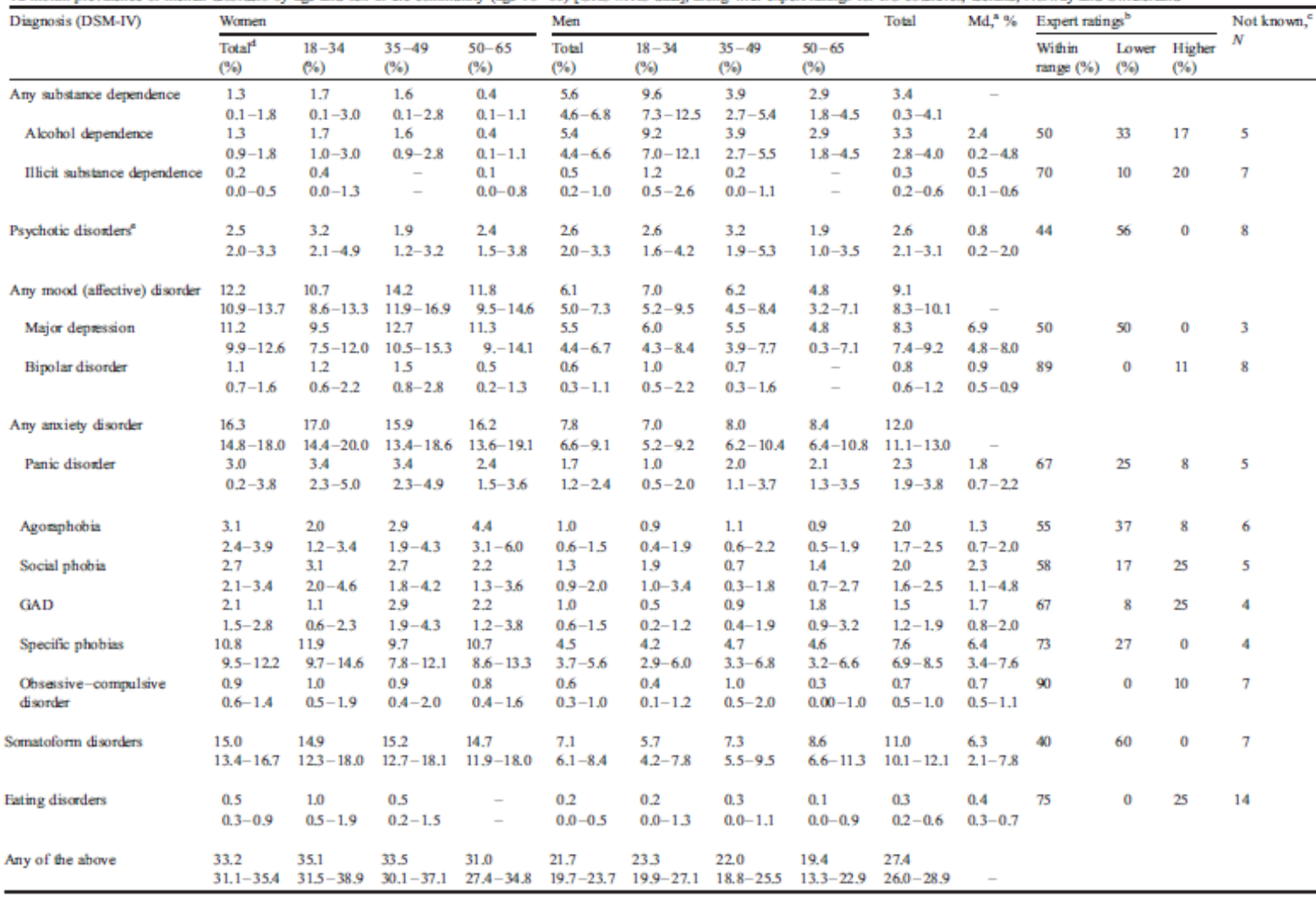

"Medians of all available European data (Table 2) with inlerquartile ranger, no median could be calculated for some aggregated diagnoses (any substance dependence, any mood disorder, any anxiety disorler, any menial disoxler).

Expert ratings whether the prevalence in own country can be negarded as within rangelowerfhigher as the listed (bolal) ocnfidence intervals, percentages based on $N-3$ (eating disorders) bo $N-14$ (majot capresion) expert stakements.

Number amang the experts $(N-17)$ rating that population based prevalence is not known for the respoctive couniry.

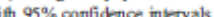

"Al1 "lower"-results frum other studies and expert ratings due to exclusively focusing on schizophrenis 
Table 4

Estimated number of subjects in the general EU population (age 18-65)

affected by mental disorders within past 12 months"

\begin{tabular}{|c|c|c|c|c|}
\hline Diagnosis (DSM-IV) & $\begin{array}{l}\text { 12-month } \\
\text { estinate } \\
\text { (mil hon) }\end{array}$ & $\begin{array}{l}\text { Lower range } \\
(\text { million })^{c}\end{array}$ & & $\begin{array}{l}\text { Upper rang } \\
\text { (millions) }\end{array}$ \\
\hline Aloohol dependence & 7.2 & 5.9 & - & 8.6 \\
\hline Illicit substance dependence & 2.0 & 1.5 & - & 2.2 \\
\hline Psychotic disorders & 3.7 & 2.8 & - & 5.4 \\
\hline Major depression & 18.4 & 17.2 & - & 19.0 \\
\hline Bipolar disorder & 2.4 & 1.7 & - & 2.4 \\
\hline Panic disorder & 5.3 & 4.3 & - & 5.3 \\
\hline Agaraphotia & 4.0 & 3.3 & - & 4.7 \\
\hline Social photia & 6.7 & 5.4 & - & 9.3 \\
\hline GAD & 5.9 & 5.3 & - & 6.2 \\
\hline Specific photrias & 18.5 & 14.4 & - & 18.6 \\
\hline OCD & 2.7 & 2.5 & - & 3.1 \\
\hline Somalofomn disonders & 18.9 & 127 & - & 21.2 \\
\hline Eating disarders & 1.2 & 1.0 & - & 1.7 \\
\hline Any mental disorder" & 82.7 & 78.5 & - & 87.1 \\
\hline \multicolumn{5}{|l|}{ Comortidity" } \\
\hline \multicolumn{5}{|l|}{ Number of diagnoses: } \\
\hline One & 56.5 & 52.7 & - & 60.5 \\
\hline Two & 15.0 & 13.1 & - & 17.1 \\
\hline Three or more & 11.2 & 9.6 & - & 13.0 \\
\hline
\end{tabular}

Total population EU countries (plus Iceland, Norway, Switzerland, age: $18-65)$ : 301.7 million.

" 12 -month estimate: missing data for coun tries were replaced by median.

"Lower range: missing data for courtries were replaced by bwer quartile.

${ }^{4}$ Upper range: missing data for countries were replaced by upper quartile.

"Aggregate figure for the diagnoses listed above ("any mental disorder", $27.4 \%$ ) and comorbidity status (number of diagnoses) hased on GHS-MHS date [10 b lower and upper range: $95 \%$ confidence intervals.

Type of treatment received by the users of formal health services (acoording to 12 month disorders; ESEMeD data)

\begin{tabular}{|c|c|c|c|c|c|}
\hline & \multirow[t]{2}{*}{ Any consultabion, ${ }^{b} \%$} & \multicolumn{4}{|c|}{ Proportions among regpondents with any consultation } \\
\hline & & $\begin{array}{l}\text { Only drug } \\
\text { treatment, \% }\end{array}$ & $\begin{array}{l}\text { Only psychological } \\
\text { treatment, } \%\end{array}$ & $\begin{array}{l}\text { Drug and psychological } \\
\text { treatment, } \%\end{array}$ & None, $\%$ \\
\hline Any disarder & 25.7 & 34.0 & 18.3 & 26.5 & 21.2 \\
\hline Any mood disorder & 36.5 & 37.9 & 13.8 & 33.1 & 15.1 \\
\hline Any anxiety disorder & 26.1 & 30.8 & 19.6 & 26.5 & 23.2 \\
\hline Any aloohol disonder & 8.3 & 19.5 & 34.0 & 31.7 & 14.9 \\
\hline Only one disonder & 19.6 & 34.3 & 19.4 & 17.2 & 29.1 \\
\hline Mare than one disorder & 40.0 & 33.5 & 17.0 & 373 & 12.1 \\
\hline
\end{tabular}

\section{Acknowledgements}

Data collection for epidemiological issues (chair: HUW) was coordinated by the Institute of Clinical Psychology and Psychotherapy, Technische Universität Dresden (Frank Jacobi, Elke Katze, Michael Klose, Hans-Ulrich Wittchen).

The authors would like to thank the experts participating in the data collection and commenting the prevalence data for their countries: Austria: Heinz Katschnig (Medical University of Vienna, Department of Psychiatry); Belgium: Koen Demyttenaere (Afedling Psychiatrie, Leuven), Julien Mendlewicz, Pierre Oswald (Hospital Erasme ULB, Department of Psychiatry, Brussels); Czech Republic: Eva Dragomirecka (Prague Psychiatric Center); Denmark: Povl Munk-Jörgensen (Department of Psychiatric Demography, Institute for Basic Psychiatric Research, Aarhus); Finland: Erkki Isometsä, Jouko Lönnqvist (Department for Mental Health and Alcohol Research, Helsinki); France: Jean-Pierre Le`pine (Ho` pital 
Fernand Widal, Paris); Hungary: Zoltan Rihmer (National Institute for Psychiatry and Neurology, Budapest); Iceland: Jon G. Stefa'nsson (Department of Psychiatry, National University Hospitals, Rykjavik); Italy: Carlo Faravelli (Department of Neurology and Psychiatry, University of Florence); Netherlands: Ron de Graaf (Trimbos-Instituut, Utrecht); Norway: Inger Sandanger (University of Oslo); Poland: Bozena Pietrzykowska (Institute of Psychiatry and Neurology, Warzaw); Portugal: Miguel Xavier (Clinica Universitaria de Psiquiatria e Saude Mental Faculdade de Ciencias Medicas de Lisboa, Lisbon); Spain: Jordi Alonso (Institut Municipal d'Investigacio’ Me`dica (IMIM), Barcelona); Sweden: Christer Allgulander (Karolinska Institutet, Stockholm); Switzerland: Jules Angst (University of Zurich); United Kingdom: Traolach Brugha (University of Leicester).

Additionally, the following experts provided support in at least one of the work steps: Claudine Berr (INSERM E361, Ho^ pital La Colombie`re, Montpellier, France), Lydia Fehm (Clinical Psychology and Psychotherapy, Technische Universita "t Dresden, Germany), Tom Fryers (Department of Psychiatry, University of Leicester, UK), Tomas Furmark (Department of Psychology, Uppsala University, Sweden), Renee D. Goodwin (Columbia University, Mailman School of Public Health, New York, USA), Roselind Lieb (Max- Planck-Institute for Psychiatry, Munich, Germany), Ludwig Kraus (Institute for Therapy Research, Munich, Germany), Eugene S. Paykel (University of Cambridge, UK), Lukas Pezawas (National Institute of Mental Health (NIMH), Bethesda, USA), Stefano Pini (Department of Psychiatry, Neurobiology, Pharmacology and Biotechnology, University of Pisa, Italy), Jürgen Rehm (Addiction Research Institute, Zurich, Switzerland, and Centre for Addiction and Mental Health, Toronto, Canada), Anita Riecher- Rössler (University Psychiatric Outpatient Department, Basel, Switzerland), Karen Ritchie (INSERM E361, Ho` pital La Colombie`re, Montpellier, France), Robin Room (Centre for Social Research on Alcohol and Drugs, Stockholm University, Sweden), Wulf Rössler (Psychiatric University Hospital, Zurich, Switzerland), Hans Joachim Salize (Central Institute of Mental Health, Mannheim, Germany), Wim van den Brink (Department of Psychiatry, Academic Medical Center, Amsterdam Institute of Addiction Research, Netherlands), Jim van Os (Department of Psychiatry and Neuropsychology, Maastricht University, Netherlands), Johannes Wancata (Medical University of Vienna, Department of Psychiatry, Austria).

\section{References}

- American Psychiatric Association, 1980. Diagnostic and Statistical Manual of Mental Disorders, 3rd ed. American Psychiatric Association, Washington, DC.

- American Psychiatric Association, 1987. Diagnostic and Statistical Manual of Mental Disorders, third ed. (rev.). American Psychiatric Association, Washington, DC.

- American Psychiatric Association, 1994. Diagnostic and Statistical Manual of Mental Disorders, 4th ed. American Psychiatric Association, Washington, DC.

- $\quad$ Andlin-Sobocki, P., Jönsson, B., Wittchen, H.-U., Olesen, J., 2005. Cost of disorders of the brain in Europe. Eur. J. Neurol. 12 (Suppl. 1), 1-27.

- $\quad$ Andrade, L., Caraveo-Anduaga, J.J., Berglund, P., Bijl, R., Kessler, R.C., Demler, O., Walters, E.E., Kylyc, C., Offord, D., Üstün, T.B., Wittchen, H.-U., 2000. Cross-national comparisons of the prevalences and correlates of mental disorders. B. World Health Organ. 78, 413-426.

- Andrade, L., Caraveo-Anduaga, J.J., Berglund, P.A., Bijl, R.V., de Graaf, R., Vollebergh, W.A.M., Dragomirecká, E., Kohn, R., Keller, M.B., Kessler, R.C., Kawakami, N., Kilic, C., Offord, D., Üstün, T.B., Wittchen, H.-U., 2003. The epidemiology of major depressive episodes: results from the International Consortium of Psychiatric Epidemiology (ICPE) Surveys. Int. J. Meth. Psych. Res. 12, 3-21. 
- Angst, J., Dobler-Mikola, A., Binder, J., 1984. The Zurich Study. A prospective epidemiological study of depressive, neurotic and psychosomatic syndromes: I. Problem, methodology. Eur. Arch. Psychiatr. Neurol. Sci. 234, 13-20.

- $\quad$ Angst, J., Gamma, A., Gastpar, M., Lépine, J.-P., Mendlewicz, J., Tylee, A., 2002. Gender differences in depression. Eur. Arch. Psychiatry Clin. Neurosci. 252, 201-209.

- $\quad$ Angst, J., Gamma, A., Endrass, J., Goodwin, R., Ajdacic, V., Eich, D., Rössler, W., 2004. Obsessive-compulsive severity spectrum in the community: prevalence, comorbidity, and course. Eur. Arch. Psychiatry Clin. Neurosci. 254, 156-164.

- Ansseau, M., 1999. Épidémiologie des troubles Psychiatiques dans la Province de Luxembourg. Brochure editée par la plate-forme de concertation psychiatrique de la Provence de Luxembourg.

- Arnarson, E.Ö., Gudmundsdottir, A., Boyle, G.J., 1998. Six-months prevalence of phobic symptoms in Iceland: an epidemiological postal survey. J. Clin. Psychol. 54, 257-265.

- Ayuso-Mateos, J.L., 2001. Depressive disorders in Europe: prevalence figures from the ODIN study. Br. J. Psychiatr. 179, 308-316.

- Baruffol, E., 1993. Anxiety, depression, somatization and alcohol abuse. Prevalence rates in a general Belgian community sample. Acta Psychiatr. Belg. 93, 136-153.

- Bech, P., Rasmussen, N.-A., Raabaek Olsen, L., Noerholm, V., Abildgaard, W., 2001. The sensitivity and specificity of the Major Depression Inventory using the present state examination as the index of diagnostic validity. J. Affect. Disord. 66, 159-164.

- Beck, A.T., Ward, C.H., Mendelson, M., Mock, J., Erbaugh, J., 1961. An inventory for measuring depression. Arch. Gen. Psychiatry 4, 561-571.

- $\quad$ Becker, E.S., Türke, V., Neumer, S., Soeder, U., Krause, P., Margraf, J., 2000. Incidence and prevalence rates of mental disorders in a community sample of young women: results of the „Dresden Study“. In: Manz, R., Kirch, W. (Eds.), Public Health Research and Practice: Report of the Public Health Research Association Saxony II. Roederer, Regensburg, pp. 259-291.

- Berr, C., Wancata, J., Ritchie, K., 2005. Prevalence of dementia in the elderly in Europe. Eur. Neuropsychopharmacol. 15, 463-471.

- $\quad$ Berwick, D.M., Murphy, J.M., Goldman, P.A., 1991. Performance of a five-item mental health screening test. Med. Care 29, 169-176.

- Bijl, R.V., Ravelli, A., 2000a. Current and residual functional disability associated with psychopathology: findings from the Netherlands Mental Health Survey and Incidence Study (NEMESIS). Psychol. Med. 30, 657-668.

- Bijl, R.V., Ravelli, A., 2000b. Psychiatric morbidity, service use, and need for care in the general population: results of The Netherlands Mental Health Survey and Incidence Study. Am. J. Public Health 90, 602-607.

- Bijl, R.V., Ravelli, A., van Zessen, G., 1998. Prevalence of psychiatric disorder in the general population: results of the Netherlands Mental Health Survey and Incidence Study (NEMESIS). Soc. Psychiatry Psychiatr. Epidemiol. 33, 587-595.

- $\quad$ Bijl, R.V., de Graaf, R., Hiripi, E., Kessler, R.C., Kohn, R., Offord, D.R., Üstün, T.B., Vicente, B., Vollebergh, W.A.M., Walters, E.E., Wittchen, H.-U., 2003. The prevalence of treated and untreated mental disorders in five countries. Health Aff. 22, 122-133.

- Coulter, A., Magee, H., 2003. The European Patient of the Future. Open University Press, Philadelphia.

- de Girolamo, G., Polidori, G., Morosini, P., Mazzi, F., Serra, G., Visonà, G., Falsirollo, F., Rossi, A., Scarpino, V., Reda, V., 2005. La prevalenza dei disturbi mentali in Italia. II progetto ESeMED-WMH. Una sintesi. M. d. Salute, Roma.

- $\quad$ Dowrick, C., Casey, P., Dalgard, O., Hosman, C., Lehtinen, V., Vazquez-Barquero, J.L., Wilkinson, G., 1998. Outcomes of Depression International Network (ODIN)—background, methods and field trials. Br. J. Psychiatr. 172, 359-363.

- Dubini, A., Mannheimer, R., Pancheri, P., 2001. Depression in the community: results of the first Italian survey. Int. Clin. Psychopharmacol. 16, 49-53.

- ESEMeD/MHEDEA 2000 Investigators, 2002. The European Study of the Epidemiology of mental Disorders (ESEMeD/MHEDEA 2000). Project: rationale and methods. Int. J. Methods Psychiatr. Res. 11,55-67. 
- ESEMeD/MHEDEA 2000 Investigators, 2004a. Prevalence of mental disorders in Europe: results from the European Study of the Epidemiology of Mental Disorders (ESEMeD) project. Acta Psychiatr. Scand. 109 (Suppl. 1), 21-27.

- ESEMeD/MHEDEA 2000 investigators, 2004b. Disability and quality of life impact of mental disorders in Europe: results from the European Study of the Epidemiology of Mental Disorders (ESEMeD) project. Acta Psychiatr. Scand. 109 (Suppl. 1), 38-46.

- ESEMeD/MHEDEA 2000 Investigators, 2004c. Use of mental health services in Europe: results from the European Study of the Epidemiology of Mental Disorders (ESEMeD) project. Acta Psychiatr. Scand. 109 (Suppl. 1), 47-54.

- EUROSTAT, 2004. Statistical Office of the European Communities (http://www.eu.int/comm/eurostat): statistics on population and social conditions. Databank query via http://europa.eu.int/comm/eurostat/newcronos/reference/display.do?screen=welcomeref \& open=/popul/Popula/main/demo/dpop \& language=en \& product=EU_population_social_conditions and root=EU_population_social_conditions \& scrollto $=0$ (Accessed 1 September 2004).

- Faravelli, C., 2004. The Sesto Fiorentino study: point and one year prevalences of psychiatric disorders in an Italien community sample using clinical interviewers. Psychother. Psychosom. 73, 226-234.

- Faravelli, C., Bartolozzi, D., Cimminiello, L., Cecchi, C., Cosci, F., D’Adamo, D., Di Matteo, C., DiPrimio, C., Fabbri, C., Lo Iacono, B., Paionni, A., Perone, A., Rosi, S., Scarpato, M.A., Serena, A., Taberna, A., 2001. The Florence psychiatric interview. Int. J. Methods Psychiatr. Res. 10, 157-171.

- Fehm, L., Pelissolo, A., Furmark, T., Wittchen, H.-U., 2005. Size and burden of social phobia in Europe. Eur. Neuropsychopharmacol. 15, 453-462.

- Fryers, T., Brugha, T., Morgan, Z., Smith, J., Hill, T., Carta, M., Lehtinen, V., Kovess, V., 2004. Prevalence of psychiatric disorder in Europe: the potential and reality of meta-analysis. Soc. Psychiatry Psychiatr. Epidemiol. 39, 899-905.

- Goldberg, D.P., Hillier, V.F., 1979. A scaled version of the general health questionnaire. Psychol. Med. 9, 139-145.

- Goldberg, D., Huxley, P., 1980. Mental Illness in the Community: The Pathway to Psychiatric Care. Tavistock, London.

- Goodwin, R., Faravelli, C., Rosi, S., Cosci, F., Truglia, E., de Graaf, R., Wittchen, H.-U., 2005. The epidemiology of panic disorder and agoraphobia in Europe. Eur. Neuropsychopharmacol. 15, 435-443.

- Greenberg, P.E., Kessler, R.C., Nells, T.L., Finkelstein, S.N., Berndt, E.R., 1996. Depression in the workplace: an economic perspective. In: Feighner, J.P., Boyer, W.F. (Eds.), Selective Serotonin Reuptakers: Advances in Basic Research and Clinical Practice. Wiley, New York.

- Greenberg, P.E., Sisitsky, T., Kessler, R.C., Finkelstein, S.N., Berndt, E.R., Davidson, J.R.T., Ballenger, J.C., Fyer, A.J., 1999. The economic burden of anxiety disorders in the 1990s. J. Clin. Psychiatry 60, 427-435.

- Hällström, T., Damström, T., Thakker, K., Forsell, Y., Lundber, I., Tinghög, P., 2003. The PART Study. A Population Based Study of Mental Health in the Stockholm County: Study Design. Phase 1 (1998-2001). Samhällsmedicin, Stockholm.

- Hofstra, M.B., van der Ende, J., Verhulst, F.C., 2001. Adolescents's selfreported problems as predictors of psychopathology in adulthood: 10-year follow-up study. Br. J. Psychiatr. 179, 203-209.

- Jacobi, F., Wittchen, H.-U., Holting, C., Sommer, S., Lieb, R., Höfler, M., Pfister, H., 2002. Estimating the prevalence of mental and somatic disorders in the community: aims and methods of the German National Health Interview and Examination Survey. Int. J. Methods Psychiatr. Res. 11, 1-18.

- Jacobi, F., Wittchen, H.-U., Hölting, C., Höfler, M., Müller, N., Pfister, H., Lieb, R., 2004a. Prevalence, comorbidity and correlates of mental disorders in the general population: results from the German Health Interview and Examination Survey (GHS). Psychol. Med. 34, 597611. 
- Jacobi, F., Klose, M., Wittchen, H.-U., 2004b. Psychische Störungen in der Allgemeinbevölkerung: Inanspruchnahme von Gesundheitsleistungen und Ausfalltage. Bundesgesundheitsblatt Gesundh. Forsch. Gesundh. Schutz 47, 736-744.

- Jenkins, R., Bebbington, P., Brugha, T., Farrell, M., Gill, B., Lewis, G., Meltzer, H., Petticrew, M., 1997. The national psychiatric morbidity surveys of Great Britain—strategy and methods. Psychol. Med. 27, 765-774.

- Jenkins, R., Lewis, G., Bebbington, P., Brugha, T., Farrell, M., Gill, B., Meltzer, H., 1997. The national psychiatric morbidity surveys of Great Britain-initial findings from the household survey. Psychol. Med. 27,775-789.

- Kessler, R.C., 2004. Prevalence, severity, and unmet need for tretment of mental disorders in the world health organization—world mental health surveys. J. Am. Med. Assoc. 291 (21), 2581-2590.

- Kessler, R.C., Frank, R.G., 1997. The impact of psychiatric disorders on work loss days. Psychol. Med. 27, 861-873.

- Kessler, R.C., McGongale, K.A., Zhao, S., Nelson, C.B., Hughes, M., Ehleman, S., Wittchen, H.-U., Kendler, K.S., 1994. Lifetime and 12-month prevalence of DSM-III-R psychiatric disorders in the United States: results from the National Comorbidity Survey. Arch. Gen.

- Psychiatry 51, 8-19.

- $\quad$ Kessler, R.C., Andrews, G., Mroczek, D., Üstün, T.B., Wittchen, H.-U., 1998. The world health organization Composite International Diagnostic Interview Short-Form (CIDI-SF). Int. J. Methods Psychiatr. Res. 7(4), 171-185.

- $\quad$ Kessler, R.C., Merikangas, K.R., Berglund, P., Eaton, W.W., Koretz, D.S., Walters, E.E., 2003. Mild disorders should not be eliminated from the DSM-V. Arch. Gen. Psychiatry 60, 1117-1122.

- $\quad$ Kessler, R., Berglund, P., Chiu, W.T., Demler, O., Heeringa, S., Hiripi, E., Jin, R., Pennell, B.E., Walters, E.E., Zaslavsky, A., Zheng, H., 2004. The US National Comorbidity Survey Replication (NCS-R): an overview of design and field procedures. Int. J. Methods Psychiatr.

- Res. 13, 69-92.

- Knäuper, B., Wittchen, H.-U., 1994. Diagnosing major depression in the elderly: evidence for response bias in standardized diagnostic interviews? J. Psychiatr. Res. 28, 147- 164.

- Kringlen, E., Torgersen, S., Cramer, V., 2001. A Norwegian psychiatric epidemiological study. Am. J. Psychiatry 158, 1091-1098.

- Lepine, J.P., Gastpar, M., Mendlewicz, J., Tylee, A., 1997. Depression in the community: the first pan-European study DEPRES (Depression Research in European Society). Int. Clin. Psychopharmacol. 12, 19-29.

- Lewis, G., Pelosi, A.J., Araya, R., Dunn, G., 1992. Measuring psychiatric disorder in the community: a standardized assessment for use by lay interviewers. Psychol. Med. 22, 465486.

- Lieb, R., Isensee, B., von Sydow, K., Wittchen, H.-U., 2000. The Early Developmental Stages of Psychopathology Study (EDSP): a methodological update. Eur. Addict. Res. 6, 170-182.

- Lieb, R., Becker, E.S., Altamura, C., 2005. The epidemiology of generalized anxiety disorder in Europe. Eur. Neuropsychopharmacol. 15, 445-452.

- Lindal, E., Stefansson, J.G., 1993. The lifetime prevalence of anxiety disorders in Iceland as estimated by the US national institute of mental health. Diagnostic interview schedule. Acta Psychiatr. Scand. 88 (1), 29-34.

- $\quad$ Lindeman, S., Hamalainen, J., Isometsa, E., Kaprio, J., Poikolainen, K., Heikkinen, M., Aro, H., 2000. The 12 month prevalence and risk factors for major depressive episode in Finland: representative sample of 5993 adults. Acta Psychiatr. Scand. 102, 178-184.

- Margraf, J., Schneider, S., Ehlers, A., 1994. DIPS: Diagnostisches Interview bei psychischen Störungen. Springer, Berlin.

- $\quad$ McConnell, P., Bebbington, P., McClelland, R., Gillespie, K., Houghton, S., 2002. Prevalence of psychiatric disorder and the need for psychiatric care in Nothern Ireland. Population study in the District of Derry. Br. J. Psychiatr. 181, 214-219.

- Meltzer, H., Baljit, G., Petticrew, M., Hinds, K., 1995. The prevalence of psychiatric morbidity among adults living in private households. HSMO/PCS Reports, London. 
- Merikangas, K.R., Mehta, R.L., Molnar, B.E., Walters, E.E., Swendsen, J.D., AguilarGaxiola, S., Bijl, R., Borges, G., Caraveo-Anduaga, J.J., DeWitt, D.J., Kolody, B., Vega, W.A., Wittchen, H.-U., Kessler, R.C., 1998. Comorbidity of substance use disorders with mood and anxiety disorders: results of the International Consortium of Psychiatric Epidemiology. Addict. Behav. 23 (6),893-907.

- Meyer, C., Rumpf, H.-J., Hapke, U., Dilling, H., John, U., 2000. Lebenszeitprävalenz psychischer Störungen in der erwachsenen Allgemeinbevölkerung: Ergebnisse der TACOSStudie. Nervenarzt 71, 535-542.

- Meyer, C., Rumpf, H.-J., Hapke, U., John, U., 2001. Prevalence of DSM-IV psychiatric disorders including nicotine dependence in the general population: results from the northern german TACOS study. Neurol. Psychiatr. Br. 9, 75- 80.

- Murray, C.J., Lopez, A.D., 1996. Evidence-based health policy-lessons from the Global Burden of disease study. Science 274, 740-743.

- Narrow, W.E., Rae, D.S., Robins, L.N., Regier, D.A., 2002. Revised prevalence estimates of mental disorders in the United States-using a clinical significance criterion to reconcile 2 surveys' estimates. Arch. Gen. Psychiatry 59, 115-123.

- OECD,, 2005. OECD Factbook 2005. Economic, Environmental and Social Statistics. OECD Publishing, London.

- Olesen, J., Leonardi, M., 2003. The burden of brain diseases in Europe. Eur. J. Neurol. 10, 471-477.

- Olsen, J., 2004. Prevalence of major depression and stress indicators in the Danish general population. Acta Psychiatr. Scand. 109, 96-103.

- Paykel, E.S., Brugha, T., Fryers, T., 2005. Size and burden of depressive disorders in Europe. Eur. Neuropsychopharmacol. 15, 411-423.

- Pini, S., de Queiroz, V., Pagnin, D., Pezawas, L., Angst, J., Cassano, G.B., Wittchen, H.-U., 2005. Prevalence and burden of bipolar disorders in European countries. Eur. Neuropsychopharmacol. 15,425-434.

- $\quad$ Pirkola, S., Isometsä, E., Suvisaari, J., Aro, H., Joukamaa, M., Poikolainen, K., Koskinen, S., Aromaa, A., Lönnqvist, J., 2005. DSM-IV mood-, anxiety and alcohol use disorders and their comorbidity in the Finnish general population. Results from the health 2000 study. Soc. Psychiatry Psychiatr. Epidemiol. 40, 1-10.

- Rehm, J., Room, R., van den Brink, W., Jacobi, F., 2005a. Alcohol use disorders in EU countries and Norway: an overview of the epidemiology. Eur. Neuropsychopharmacol. 15, 377-388.

- Rehm, J., Room, R., van den Brink, W., Kraus, L., 2005b. Problematic drug use and drug use disorders in EU countries and Norway: an overview of the epidemiology. Eur. Neuropsychopharmacol. 15,389-397.

- $\quad$ Rice, D.P., Miller, L.S., 1998. Health economics and cost implications of anxiety and other mental disorders in the United States. Br. J. Psychiatr. 173 (Suppl. 34), 4-9.

- $\quad$ Rihmer, Z., Szadoczky, E., Furedi, J., Kiss, K., Papp, Z., 2001. Anxiety disorders comorbidty in bipolar I, bipolar II and unipolar major depression: results from a population-based study in Hungary. J. Affect. Disord. 67, 175-179.

- Robins, L.N., Marcus, S.M., 1987. The diagnostic screening procedure writer. A tool to develop individualized screening procedures. Med. Care 25 (Suppl. 12), 106-122.

- Robins, N.L., Regier, D.A. (Eds.), 1991. Psychiatric Disorders in America: The Epidemiologic Catchment Area Study. The Free Press, New York.

- $\quad$ Robins, L.N., Helzer, J.E., Croughan, J., Ratcliff, K.S., 1981. National Institute of Mental Health Diagnostic Interview Schedule: its history, characteristics and validity. Arch. Gen. Psychiatry 38, 381-389.

- $\quad$ Robins, L.N., Wing, J., Wittchen, H.-U., Helzer, J.E., Babor, T.F., Burke, J., Farmer, A., Jablenski, A., Pickens, R., Regier, D.A., Sartorius, N., Towle, L.H., 1988. The composite international diagnostic interview: an epidemiological instrument suitable for use in conjunction with different diagnostic systems and in different cultures. Arch. Gen. Psychiatry 45, 1069-1077. 
- Rössler, W., Salize, H.J., van Os, J., Riecher-Rössler, A., 2005. Size of burden of schizophrenia and psychotic disorders. Eur. Neuropsychopharmacol. 15, 399-409.

- Sartorius, N., Üstün, T.B., Costa, E., Silva, J.A., Goldberg, D., Lécrubier, Y., Ormel, H., Korff, M., Wittchen, H.-U., 1993. An international study of psychological problems in primary care. preliminary report from the world health organization collaborative project on „psychological problems in general health care“. Arch. Gen. Psychiatry 50, 819-824.

- Singleton, N., Bumpstead, R., O’Brien, M., Lee, A., Meltzer, H., 2001. Psychiatric morbidity among adults living in private households. National Statistics, vol. 154. The Stationery Office, London.

- Sheehan, D.V., Lecrubier, Y., Sheehan, K.H., Amorim, P., Janavs, J., Weiller, E., Hergueta, T., Baker, R., Dunbar, G.C., 1998. The Mini-International Neuropsychiatric Interview (M.I.N.I.): the development and validation of a structured diagnostic psychiatric interview for DSMIV and ICD-10. J. Clin. Psychiatry 59 (20), 22-33.

- $\quad$ Spijker, J., de Graaf, R., Bijl, R.V., Beekman, A.T.F., Ormel, J., Nolen, W.A., 2004. Functional disability and depression in the general population. Results from the Netherlands Mental Health Survey and Incidence Study (NEMESIS). Acta Psychiatr. Scand. 110, 208214.

- Stefansson, J.G., Lindal, E., Bjoernsson, J.K., Gudmundsdottir, A., 1991. Lifetime prevalence of specific mental disorders among people born in Iceland in 1931. Acta Psychiatr. Scand. 84 (2), 142-149.

- $\quad$ Szadoczky, E., Rihmer, Z., Papp, Z., Füredi, J., 1997. The prevalence of affective and anxiety disorders in preimary care practice in Hungary. J. Affect. Disord. 43, 239-244.

- $\quad$ Szadoczky, E., Papp, Z., Vitrai, J., Rihmer, Z., Furedi, J., 1998. The prevalence of major depressive and bipolar disorders in Hungary. J. Affect. Disord. 50, 153-162.

- Szadoczky, E., Papp, Z., Vitrai, J., Füredi, J., 2000. A hangulat- es szorongasos zavarok elöfordulasa a felnott magyar lakossag köreben. Orv. Hetil. 141, 17-22.

- Szadoczky, E., Rihmer, Z., Papp, Z., Vitrai, J., Füredi, J., 2002. Gender differences in major depressive disorders in a Hungarian community survey. Int. J. Psychiatry Clin. 6, 31-37.

- $\quad$ ten Have, M., de Graaf, R., Vollebergh, W., Beekman, A., 2004. What depressive symptoms are associated with the use of care services? Results from the Netherlands Mental Health Survey and Incidence Study (NEMESIS). J. Affect. Disord. 80, 239-248.

- The WHO World Mental Health Survey Consortium, 2004. Prevalence, severity, and unmet need for treatment of mental disorders in the World Health Organization World Mental Health Surveys. J. Am. Med. Assoc. 291, 2581-2589.

- Tylee, A., Gastpar, M., Lepine, J.P., 1999. DEPRES II (Depression Research in European Society II): a patient survey of the symptoms, disability and current management of depression in the community. Int. Clin. Psychopharmacol. 14, 139-151.

- Tylee, A., Gastpar, M., Lepine, J.P., 1999. Identification of depressed patient types in the community and their treatment needs: findings from the DEPRES II (Depression Research in European Society II. Survey). Int. Clin. Psychopharmacol. 14, 153-165.

- Vega, W.A., Aguilar-Gaxiola, S., Andrade, L., Bijl, R.V., Borges, G., Caraveo-Anduaga, J.J., DeWit, D.J., Heeringa, S.G., Kessler, R.C., Kolody, B., Merikangas, K.R., Molnar, B.E., Walters, E.E., Warner, L.A.,Wittchen, H.-U., 2002. Prevalence and age of onset for drug use in seven international sites: results from the international consortium of psychiatric epidemiology. Drug Alcohol Depend. 68, 285-297.

- $\quad$ Von Campenhausen, S., Bornschein, B., Wick, R., Bötzel, K., Sampaio, C., Poewe, W., Oleson, J., Oertel, W., Siebert, U., Berger, K., Dodel, R., 2005. Prevalence and incidence of Parkinson's disease in Europe. Eur. Neuropsychopharmacol. 15, 473-490.

- Wacker, H.-R., 1995. Anxiety and Depression. An Epidemiological Investigation. Huber, Bern.

- $\quad$ Ware, J.E., Kosinski, M., Keller, S.D., 1996. A 12-item short form health survey. Med. Care 34, 220-233.

- Weissman, M.M., Wickramaratne, P.J., Greenwald, S., Hsu, H.Y., Ouellette, R., Robins, L.N., Escobar, J.I., Bland, R., Newman, S., Orn, H., Canino, G.J., Rubiostipec, M., Wittchen, H.-U., Essau, C.A., Faravelli, C., Incerpi, G., Deglinnocenti, B.G., Aiazzi, L., Pallanti, S., Lepine, 
J.P., Pariente, P., Lellouch, J., Karam, E., Wells, J.E., Joyce, P.R., Oakley-Browne, M., Bushnell, J.A., Hwu, H.-G., Yeh, E.K., Chang, L.Y., Klerman, G.L., Leon, A.C., Lavori, P., Warshaw, M., Maier, W., Marx, A., Lichtermann, D., Minges, J., Heun, R., Halmayer, J., 1992. The changing rate of major depression—cross-national comparisons. J. Am. Med. Assoc. 268, 3098-3105.

- Weissman, M.M., Bland, R.C., Canino, G.J., Greenwald, S., Hwu, H.-G., Lee, C.-K., Newman, S.C., Oakley-Browne, M.A., Rubio-Stipec, M., Wickramaratne, P.J., Wittchen, H.U., Yeh, E.-K., 1994. The Cross National Epidemiology of obsessive- compulsive disorder. J. Clin. Psychiatry 55 (Suppl. 3), 5-10.

- Weissman, M.M., Bland, R.C., Canino, G.J., Faravelli, C., Greenwald, S., Hwu, H.-G., Joyce, P.R., Karam, E.G., Lee, C.-K., Lellouch, J., Lépine, J.-P., Newman, S.C., Rubio-Stipec, M., Wells, J.E., Wickramaratne, P.J., Wittchen, H.-U., Yeh, E.-K., 1996. Cross-national epidemiology of major depression and bipolar disorder. J. Am. Med. Assoc. 276, 293-299.

- Weissman, M.M., Bland, R.C., Canino, G.J., Faravelli, C., Greenwald, S., Hwu, H.-G., Joyce, P.R., Karam, E.G., Lee, C.-K., Lellouch, J., Lépine, J.-P., Newman, S.C., Oakley-Browne, M.A., Rubio-Stipec, M., Wells, J.E., Wickramaratne, P.J., Wittchen, H.-U., Yeh, E.-K., 1997. The crossnational epidemiology of panic disorder. Arch. Gen. Psychiatry 54, 305-309.

- Weissman, M.M., Bland, R.C., Canino, G.J., Greenwald, S., Hwu, H.-G., Joyce, P.R., Karam, E.G., Lee, C.-K., Lellouch, J., Lépine, J.-P., Newman, S.C., Rubio-Stipec, M., Wells, J.E., Wickramaratne, P.J., Wittchen, H.-U., Yeh, E.-K., 1999. Prevalence of suicide ideation and suicide attempts in nine countries. Psychol. Med. 29, 9-17.

- Wing, J.K., Barbor, T., Brugha, T., Cooper, J.E., Giel, R., Jablenski, A., Regier, D., Sartorius, N., 1990. SCAN: Schedules for Clinical Assessment in Neuropsychiatry. Arch. Gen. Psychiatry 47, 589-593.

- Wittchen, H.-U., 1994. Reliability and validity studies of the WHO-Composite International Diagnostic Interview (CIDI): a critical review. J. Psychiatr. Res. 28, 57-84.

- Wittchen, H.-U., 1996a. What is comorbidity—fact or artefact? Br. J. Psychiatr. 168 (Suppl. 30), 7-8.

- Wittchen, H.U., 1996b. Critical issues in the evaluation of comorbidity of psychiatric disorders. Br. J. Psychiatr. 168 (Suppl. 30), 9-16.

- Wittchen, H.-U., 2000. Met and unmet need for interventions in community cases with anxiety disorders. In: Andrews, G., Henderson, S. (Eds.), Unmet Need in Psychiatry. Problems, Resources, Responses. Cambridge University Press, Cambridge, pp. 256-276.

- Wittchen, H.-U., 2001. Diagnosis and classification of mental and behavioral disorders. In: Smelser, N.J., Baltes, P.B. (Eds.), International Encyclopedia of the Social and Behavioral Sciences. Pergamon, Oxford, pp. 9628-9639.

- Wittchen, H.-U., 2002. Generalized anxiety disorder: prevalence, burden and cost to society. Depress. Anxiety 16, 162-171.

- Wittchen, H.-U., 2004. Continued needs for epidemiological studies of mental disorders in the community. Psychother. Psychosom. 73, 197-206.

- Wittchen, H.-U., Lachner, G., Wunderlich, U., Pfister, H., 1998a. Test-retest reliability of the computerized DSM-IV version of the Munich-Composite International Diagnostic Interview (M-CIDI). Soc. Psychiatry Psychiatr. Epidemiol. 33, 568-578.

- $\quad$ Wittchen, H.-U., Nelson, C.B., Lachner, G., 1998b. Prevalence of mental disorders and psychosocial impairments in adolescents and young adults. Psychol. Med. 28, 109-126.

- $\quad$ Wittchen, H.-U., Pfister, H., Schmidtkunz, B., Winter, S., and Müller, N., 2000. German National Health Interview and Examination Survey-Mental Health Supplement (GHS-MHS): Part 2. Tables and instructions for public use file (supplement to final report BMBFBW $01 \mathrm{EH}$ 9701/8). Munich: Max-Planck-Institute for Psychiatry, Clinical Psychology and Epidemiology. (The public use file can be ordered at: jacobi@psychologie.tu-dresden.de.)

- Wittchen, H.-U., Kessler, R.C., Üstün, T.B., 2001. Properties of the Composite International Diagnostic Interview (CIDI) for measuring mental health outcome. In: Tansella, M., Thornicroft, G. (Eds.), Mental Health Outcome Measures, 2nd edR Gaskell, London, pp. 212227. 
- Wittchen, H.-U., Beesdo, K., Bittner, A., 2003. Depression—an underdiagnosed disease. Medicographia 25, 9-18.

- World Health Organization, 1978. International Classification of Diseases, 9th revision. World Health Organization, Geneva.

- World Health Organization, 1993. Tenth Revision of the International Classification of Diseases, Chapter V (F): Mental and Behavioral Disorders. Clinical Descriptions and Diagnostic Guidelines. World Health Organization, Geneva. 